\title{
Chinese Propolis Prevents Obesity and Metabolism Syndromes Induced by a High Fat Diet and Accompanied by an Altered Gut Microbiota Structure in Mice
}

\author{
Yufei Zheng ${ }^{1,2}$, Yuqi Wu ${ }^{1}$, Lingchen Tao ${ }^{1}$, Xi Chen ${ }^{1}$, Trevor Joseph Jones ${ }^{2}$, Kai Wang ${ }^{3}{ }^{\circ}$ and \\ Fuliang $\mathrm{Hu}^{1, *}$ \\ 1 College of Animal Sciences, Zhejiang University, Hangzhou 310058, China; iriszheng92@gmail.com (Y.Z.); \\ hzhzwuyuqi@163.com (Y.W.); 11817025@zju.edu.cn (L.T.); 21717031@zju.edu.cn (X.C.) \\ 2 Department of Radiation Oncology, Helen Diller Family Comprehensive Cancer Center, University of \\ California, San Francisco, San Francisco, CA 94115, USA; Trevor.Jones@ucsf.edu \\ 3 Institute of Apicultural Research, Chinese Academy of Agricultural Sciences, Beijing 100093, China; \\ kaiwang628@gmail.com \\ * Correspondence: flhu@zju.edu.cn; Tel.: +86-571-889-829-52
}

Received: 25 February 2020; Accepted: 24 March 2020; Published: 30 March 2020

\begin{abstract}
The increasing incidence of obesity poses a great threat to public health worldwide. Recent reports also indicate the relevance of obesity in metabolic diseases. Chinese propolis (CP), as a well-studied natural nutraceutical, has shown a beneficial effect on alleviating diabetes mellitus. However, few studies have investigated the effect of $\mathrm{CP}$ on weight management and energy balance. We examined the beneficial effects of dietary $\mathrm{CP}$ on weight in high-fat diet-fed female and male mice and determined whether $\mathrm{CP}$ alters gut microbiota. In this study, dietary $\mathrm{CP}$ supplementation reduces body weight and improves insulin resistance in high-fat diet (HFD)-fed mice in a dose-dependent manner. CP treatment also reverses liver weight loss and triglyceride accumulation in association with hepatic steatosis. The $16 \mathrm{~S}$ rRNA analysis of gut microbiota demonstrated that $\mathrm{CP}$ treatment modulates the composition in HFD-fed mice. Our study also suggests that male mice were more sensitive to $\mathrm{CP}$ treatment than female mice. Taken together, $\mathrm{CP}$ supplementation reduces weight gain and reverses gut microbiome dysbiosis induced by HFD. Further, the effects of $\mathrm{CP}$ treatment on metabolic biomarkers and microbiome structure differ by gender.
\end{abstract}

Keywords: Chinese propolis (CP), obesity; high-fat diet; metabolic syndromes; microbiome

\section{Introduction}

Obesity is a worldwide public health threat that is increasing among adults and youth [1]. A long-term high-fat or unbalanced diet contributes to obesity [2,3], which is reflected by the increasing global overweight ratio [4]. The incidence of obesity has reached 108 million children and 604 million adults in 2015, and the prevalence has doubled since 1980 [1]. According to a recent epidemiological survey, $37 \%$ of men and $38 \%$ of women in USA are estimated to have a body mass index (BMI) greater than $25 \mathrm{~kg} / \mathrm{m}^{2}$, which is considered as obesity [5]. High BMI contributed to 3.5 million deaths in 2010 and is the fifth leading cause of death in the world. It is also associated with the increased incidence of cancer, metabolic syndromes, and cardiovascular diseases [6]. Reports have pointed out that the significant increase in the prevalence of obesity leads to a rapid increase in type 2 diabetes, which poses a great threat to public health [7]. Therefore, it is urgent to find methods to help manage the weight gain and complications induced by obesity. 
Some scientists believe natural products offer an alternative method to exercise training that can help control the fat accumulation induced by an unhealthy diet. In a recent study, natural products, especially those rich in polyphenols, have shown great therapeutic value for the prevention and treatment of obesity via inhibiting adipocyte lipid accumulation [8]. Anhe et al. revealed that a polyphenol-rich cranberry extract could prevent diet-induced obesity and insulin resistance as well as alleviate intestinal inflammation [9]. Lama reported polyphenol-rich virgin olive oil could improve mitochondria dysfunction and non-alcoholic fatty liver disease (NAFLD) in rats fed a high-fat diet [10]. Propolis, high in polyphenols and flavonoids, is a resinous substance collected by bees from plants exudates that is mixed with wax and mandibular gland secretions [11]. Propolis has long been recognized as a natural nutraceutical by exerting great anti-inflammatory, anti-bacteria and anti-oxidant effects [11]. Studies have reported that propolis extract could boost lipid metabolism, alleviate insulin resistance, and delay obesity in high-fat diet-fed mice and rats with type 2 diabetes $[12,13]$. Additionally, ethanol-extracted propolis can regulate blood glucose, glucose metabolism, and blood lipid concentration in rats with diabetes mellitus [14]. A major component in propolis, caffeic acid phenethyl ester, has an anti-obesity effect on high-fat diet-induced adipogenesis at a very early stage by regulating cyclin D1 [15].

Studies have indicated that intestinal microbiota have various effects on human weight in response to different diets [16,17]. Changes in intestinal bacteria are believed to play a decisive role in regulating energy balance, glucose, lipid metabolism and chronic inflammation related to obesity $[18,19]$. These bacteria participate in digestive processes, energy regulation, vitamin synthesis, protection against pathogenic microorganisms, and modulation of the immunologic system [20]. Meanwhile, growing evidence has associated microbiota modulation with obesity [21]. It was suggested that certain phyla, classes, or species of bacteria could be beneficial or detrimental to obese patients. Thus, it would be promising to develop strategies for changing gut microbiota to manage obesity and obesity-related disorders [22]. Wang et al. has discovered that Chinese propolis (CP) could alleviate dextran sulfate sodium-induced colitis in rats fed a Western diet by reshaping microbiota composition [23]. Roquetto et al. tested green propolis on high-fat diet-fed mice, finding that propolis reversed the elevation of Firmicutes and inflammatory biomarkers expression induced by diet in the obese mice [24]. Here, we tested whether $\mathrm{CP}$ has positive effects on the composition of gut microbiota in high-fat diet-fed mice. To determine whether $\mathrm{CP}$ has protective effects on the gut symbiont, we correlated the anti-obesity and beneficial metabolic effect of $\mathrm{CP}$ administration on high-fat diet-fed mice with the composition of the intestinal microbiota.

\section{Materials and Methods}

\subsection{Animals and Experimental Design}

Female and male C57BL/6 6-8-week-old mice were obtained from Zhejiang Chinese Medicine University and maintained in a special pathogen-free condition. Mice were randomized by gender ( $20 \pm 0.6 \mathrm{~g}$ for female, $27 \mathrm{~g} \pm 0.5 \mathrm{~g}$ for male) to be fed a normal diet (ND), high-fat diet (HFD), high-fat diet with low-dose propolis (LP), high-fat diet with high-dose propolis (HP) for 9 weeks. LP and HP mice were treated with 150 and $300 \mathrm{mg} / \mathrm{kg}$ propolis, respectively, by gavage daily for 9 weeks. We use these doses according to the preliminary experiment. Body weight was measured every week.

The CP used was well characterized in our prior study (Table S1) [25]. The HFD (60\% kcal fat, D12492)) and ND (10\% kcal fat, D12450) mouse chows were purchased from Research Diet Inc. (New Brunswick, NJ, 08901, USA) and stored at $-20^{\circ} \mathrm{C}$.

This study was conducted in accordance with the Declaration of Helsinki, and the protocol was approved by the Ethics Committee of Zhejiang Chinese Medical University, No.SYXK, Zhejiang, 2013-0164, China. 


\subsection{Histological Analysis}

Epididymal white adipose tissue (Epi-WAT), parametrial white adipose tissue (Par-WAT), perirenal white adipose tissue (Per-WAT), mesenteric white adipose tissue (Mes-WAT), inguinal subcutaneous adipose tissue (Ing-SAT), and brown adipose tissue (BAT) were collected at autopsy upon experiment termination at 9 weeks. In addition, liver, small intestine and blood were collected.

Frozen liver sections were stained with Oil Red O. Epi-WAT, BAT, and small intestine were fixed in $4 \%$ paraformaldehyde, paraffin-embedded and sectioned at $4 \mu \mathrm{M}$. Hematoxylin and eosin staining were performed according to the standard protocol for pathological analysis.

\subsection{Biochemical Parameters}

Serum samples were collected from the heart and separated by centrifugation at $1000 \mathrm{~g}$ for $10 \mathrm{~min}$ at $4{ }^{\circ} \mathrm{C}$. Hitachi high-technologies global 7020 clinical analyzer was used to test serum biochemical parameters. The concentrations of triglycerides (TGs), cholesterol (CHOL), high-density lipoprotein (HDL), low-density lipoprotein (LDL), glucose, alanine aminotransferase (ALT) and aspartate aminotransferase (AST) were measured by DiaSys diagnostic systems (Shanghai, 200120, China). The concentration of plasma lipopolysaccharide (LPS) was measured using a Genscript ToxinSensorTM Chromogenic LAL Endotoxin Assay Kit (Jiangsu, China). The concentration of TGs in liver tissue was measured by using an Adipogenesis Kit (Sigma, 14508, USA, MAK040).

\subsection{Serum ELISA Analysis}

Serum was used to measure the levels of inflammatory cytokines. Interleukin-6 (IL-6) and tumor necrosis factor- $\alpha$ (TNF- $\alpha$ ) concentrations were measured by an enzyme-linked immunosorbent assay (ELISA) purchased from Elabscience Biotechnology (Wuhan, 430070, China).

\subsection{Glucose and Insulin Tolerance Analyses}

For the intraperitoneal glucose tolerance test (IGTT), during the 8th week of the experiment, mice were fasted for $12 \mathrm{~h}$ before receiving an IP injection of glucose $(1.5 \mathrm{~g} / \mathrm{kg})$. Blood samples were taken from the tail vein at 15, 30, 60, and 120 min post injection, and blood glucose was measured using Accucheck performa (Roche, 6980, Germany). In the 9th week, we administrated the insulin tolerance test (ITT). Mice were fasted for $6 \mathrm{~h}$ before receiving an intraperitoneal injection of insulin $(0.75 \mathrm{UI} / \mathrm{kg})$. Blood glucose levels were measured after 15, 30, 60, 120, and $180 \mathrm{~min}$. We calculated the homeostasis model index of insulin resistance based on the serum fasting blood glucose and insulin concentrations (HOMA-IR: insulin $\times$ glucose/22.5).

\subsection{Gene Expression Analysis}

The RNA of liver tissue, Epi-WAT, and BAT was extracted by RNAprep Pure tissue kit of Tiangen Biotech Co., Ltd. (Beijing, 100192, China) according to the manufacturer's protocols. The concentration of RNA in the samples was measured by NanoDrop spectrophotometer (ND-2000, NanoDrop Technologies, USA) and stored at $-80^{\circ} \mathrm{C}$. We performed cDNA synthesis and qRT-PCR as described in our previous study [25]. The housekeeping gene GAPDH was used to normalize the expression of the other target genes, and the results were expressed as $2^{-\Delta \Delta \mathrm{Ct}}$. Primers used in this study are listed in the Supplementary Materials Table S2.

\subsection{Gut Microbiota Analysis}

DNA was extracted from fresh feces ( $300 \mathrm{mg} \pm 80 \mathrm{mg}$ ) collected during the final 3 days of this study. Bacterial genomic DNA was extracted using the CTAB/SDS method. Polymerase chain reaction (PCR) reactions targeting the V3-V4 regions of the $16 \mathrm{~S}$ rDNA genes used the specific primer with the barcode (341F, 5'-CCTAYGGGRBGCASCAG-3', 806R, 5'-GGACTA CNNGGGTATCTAAT-3'). The 16S rRNA 
gene sequences were deposited in NCBI Sequence Read Archive and the corresponding accession numbers of BioProject are PRJNA562777 for male and PRJNA563139 for female.

Paired-end reads from the original DNA fragments were merged using FLASH. Sequences were analyzed using the Quantitative Insights Into Microbial Ecology (QIIME) software package, and in-house Perl scripts were used to analyze alpha (within samples) and beta (among samples) diversity. We used pick_de_novo_otus.py to pick operational taxonomic units (OTUs) by making an OTU table. Sequences with $\geq 97 \%$ similarity were assigned to the same OTUs. We picked a representative sequence for each OTU and used the RDP classifier to annotate taxonomic information for each representative sequence. In order to compute alpha diversity, we rarified the OTU table and calculated three metrics: Chao1, Observed Species, and the Shannon index. Rarefaction curves were generated based on these three metrics.

\subsection{SCFA Analysis}

Colonic digesta collected from mice at the time of autopsy were weighed and diluted with $700 \mu \mathrm{L}$ deionized water containing $0.92 \mu \mathrm{g} / \mu \mathrm{L}$ 2-ethylbutyric and then centrifuged at $10,000 \mathrm{~g}$ and $4{ }^{\circ} \mathrm{C}$ for $10 \mathrm{~min}$. The supernatant fluid was mixed with $25 \%$ metaphosphoric acid solution in a ratio of $4: 1$ at room temperature for $3 \mathrm{~h}$. The mixture was centrifuged at 10,000 $\mathrm{g}$ and $4{ }^{\circ} \mathrm{C}$ for $10 \mathrm{~min}$ and the supernatant was used for determination of short-chain fatty acids (acetic acid, propionic acid, butyric acid, isobutyric acid and isovaleric acid).

Analysis was conducted using the GC-2010 gas chromatography (Shimadzu Corporation, Kyoto, Japan) with a flame ionization detector $\left(250^{\circ} \mathrm{C}\right)$ and an ATOE-FFAP column $(30 \mathrm{~m} \times 250 \mu \mathrm{m} \times$ $0.25 \mu \mathrm{m})$. In total, $1 \mu \mathrm{L}$ of sample was injected and the injector $\left(250^{\circ} \mathrm{C}\right)$ worked in the split mode at a ratio of $10: 1$. The initial column temperature was $60^{\circ} \mathrm{C}$, rising to $220^{\circ} \mathrm{C}$ at $20^{\circ} \mathrm{C} / \mathrm{min}$. The carrier gas was $\mathrm{N}_{2}$ at a speed of $0.8 \mathrm{~mL} / \mathrm{min}$.

\subsection{Statistical Analysis}

Results were expressed as the mean \pm SEM or the mean \pm SD obtained from at least 8 biological replicates. Comparisons between controls and each treatment were performed using Student's unpaired t-test and marked with ${ }^{*} P<0.05$; ${ }^{* *} P<0.005$; ${ }^{* * *} P<0.001$ (Prism 8.0; GraphPad Software, San Diego, CA, USA).

\section{Results}

\subsection{Chinese Propolis Reduces Weight Gain in HFD-fed Mice}

We measured the body weight of female and male mice every week. As expected, the HFD group mice gained much more weight compared to the ND group, regardless of the gender (Figure 1A). The administration of LP failed to prevent HFD-fed mice from becoming overweight, while HP significantly decreased body weight under HFD in both female and male mice (Figure 1A).

Upon termination, the main adipose tissues, including Epi-WAT, Par-WAT, Per-WAT, Mes-WAT, and Ing-SAT were isolated and weighed. As shown in Figure 1B,C, HFD increased the weights of all these types of adipose tissues. The ratio of adipose tissues normalized to body weights of HFD-fed mice was significantly different compared to those on ND $(p<0.001)$. In accordance with the change in body weight, LP did not prevent the accumulation of adipose tissues in both female and male mice. In contrast, HP lowered the adipose tissue weight and the adipose/body weight ratio, especially in male mice $(p<0.005)$. In female mice, there was also a trend toward a decline.

\subsection{CP Improves Glucose Resistance and Lipid Metabolism in HFD Mice}

We measured fasting serum glucose and insulin levels to determine the impact of $\mathrm{CP}$ on glucose homeostasis and insulin sensitivity. As shown in Figure 2A, after injection of glucose, mice administrated with HP supplement reversed their glucose level faster than mice who were untreated. This also 
occurred in male mice treated with LP. The corresponding area under curve (AUC) and HOMA-IR also demonstrated that HP administration improved glucose tolerance and insulin resistance in both female and male mice (Figure 2B,C).

We also examined the effect of $\mathrm{CP}$ and HFD on serum hyperlipidemia and found that it differed depending on the gender of mice. In male mice, HFD induced a significant increase in AST, ALT, CHOL, HDL and TG levels significantly $(p<0.05)$, and CP reduced AST, CHOL, HDL and TG level significantly $(p<0.05)$, but had little effect on ALT and LDL level (Figure 2D). In contrast, HFD only increased the ALT and HDL level in female mice, and CP administration did not change the concentrations of these markers.

Previous studies have demonstrated the interaction between inflammation and obesity via serum endotoxins and inflammatory cytokines $[18,26,27]$. Thus, we examined LPS, TNF- $\alpha$ and IL- 6 concentrations in HFD-fed mice with or without CP. The mild systemic inflammation in HFD-fed mice was found effectively alleviated by CP (Figure 2E). A decreasing endotoxin (LPS) level was also found in CP-treated groups.

\section{A}
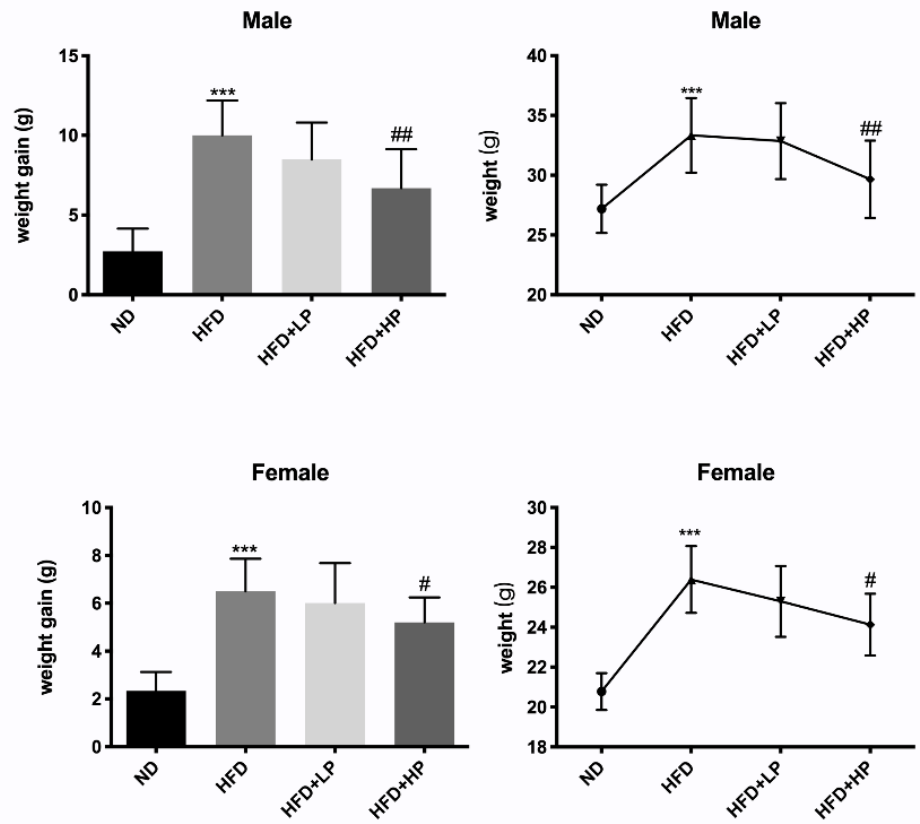

Figure 1. Cont. 
B
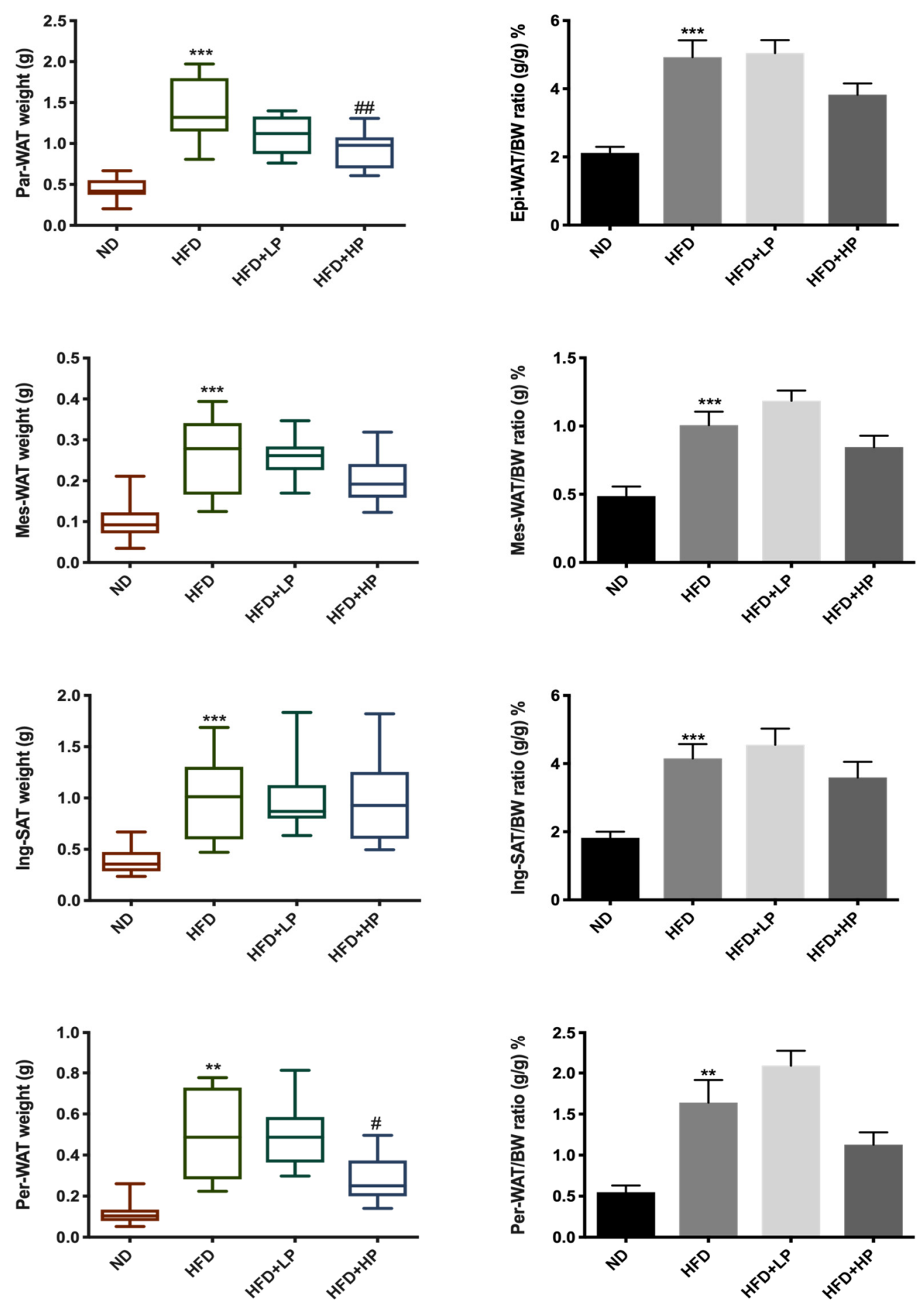

Figure 1. Cont. 

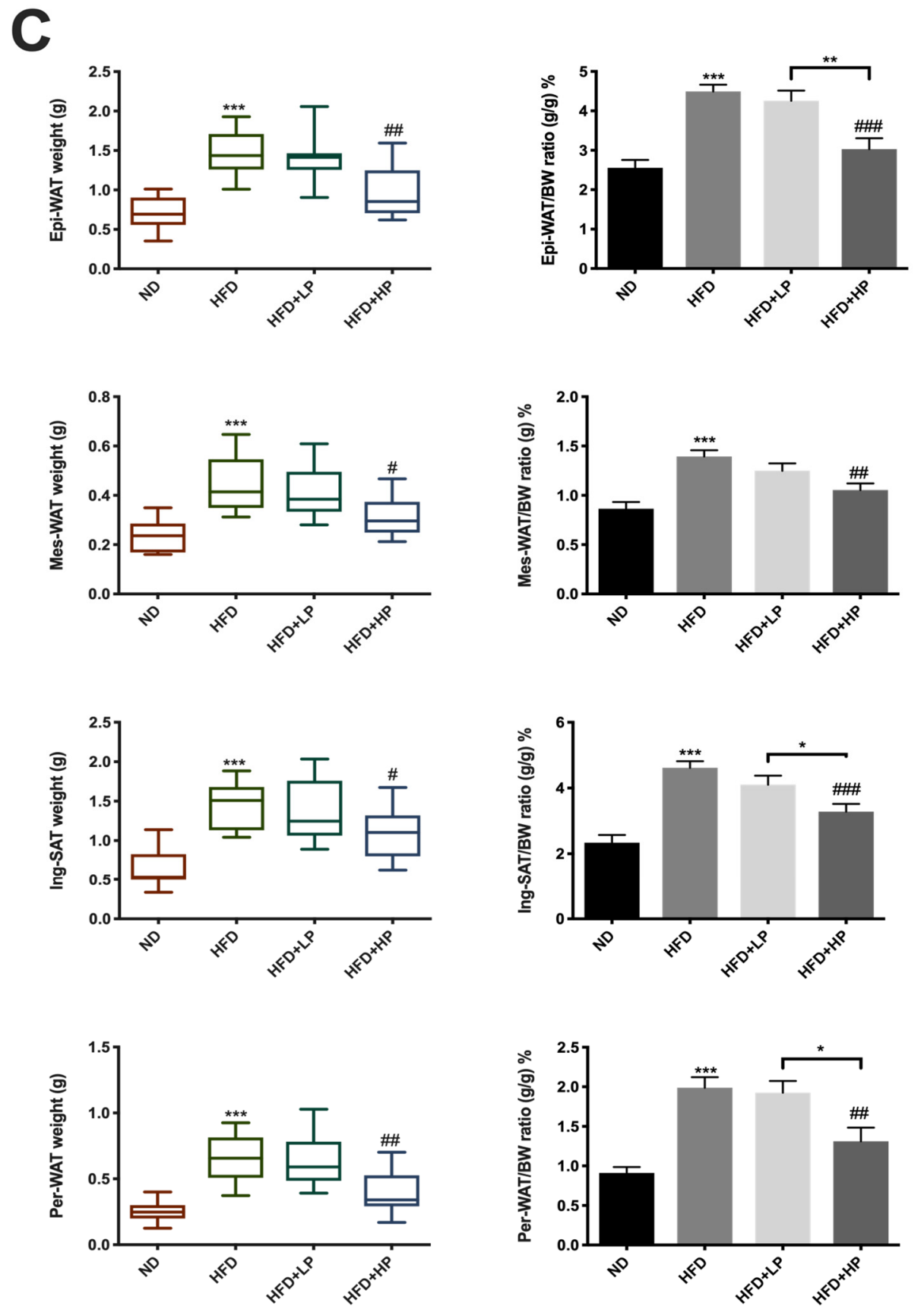

Figure 1. Chinese propolis $(\mathrm{CP})$ prevented body weight gain and fat accumulation in both female and male high-fat diet (HFD)-fed mice. (A) The mean weight gain and weight of each group of both genders. (B) The weight of parametrial white adipose tissue (Par-WAT), mesenteric white adipose tissue (Mes-WAT), inguinal subcutaneous adipose tissue (Ing-SAT) and perirenal white adipose tissue (Per-WAT) and their ratios to body weight of female mice. (C) The weight of Par-WAT, Mes-WAT, Ing-SAT and Per-WAT as well as their ratios to body weight of male mice. 

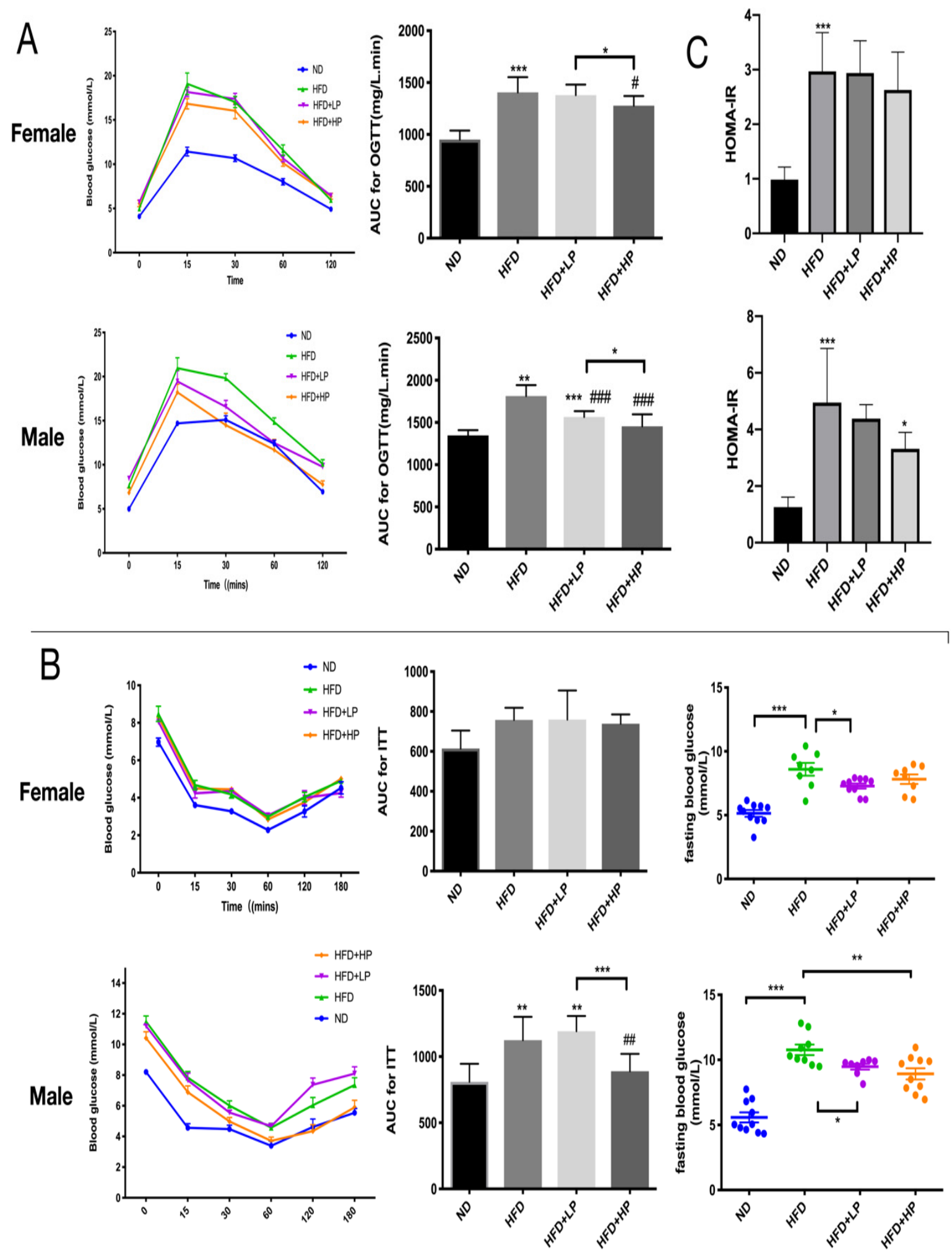

Figure 2. Cont. 
D
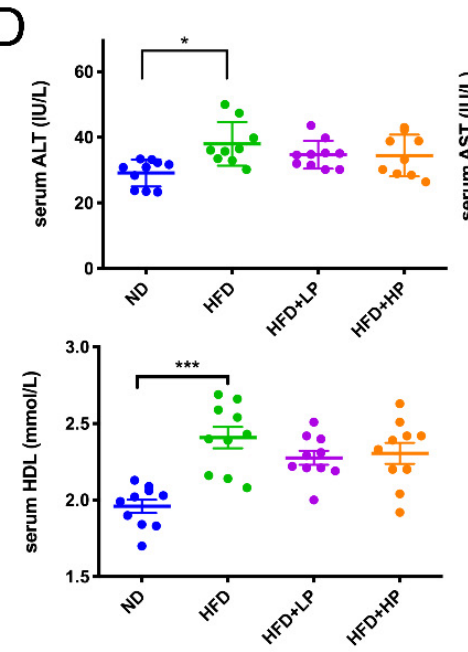

$\frac{17}{10}$
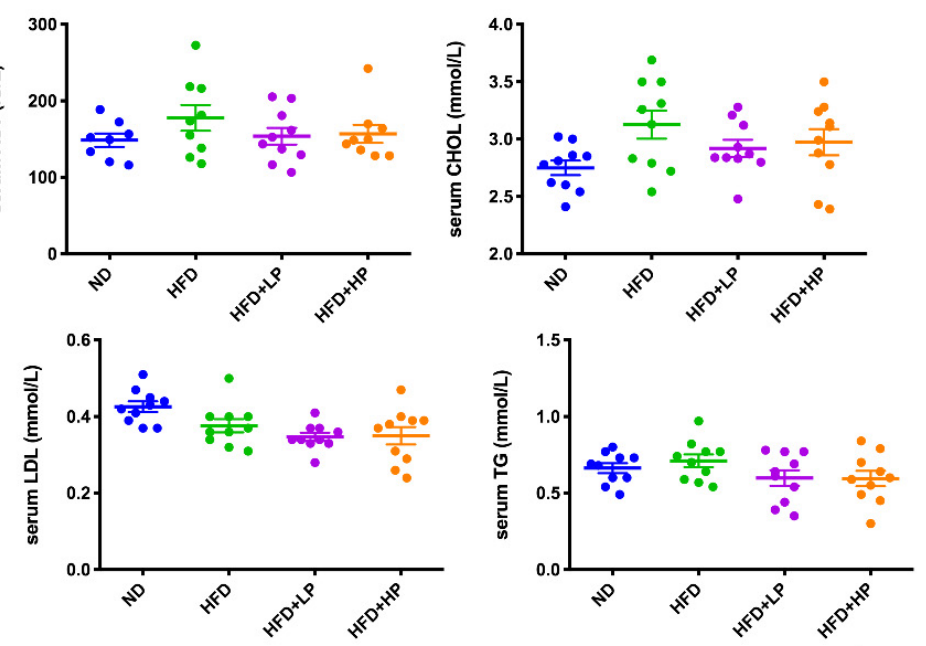
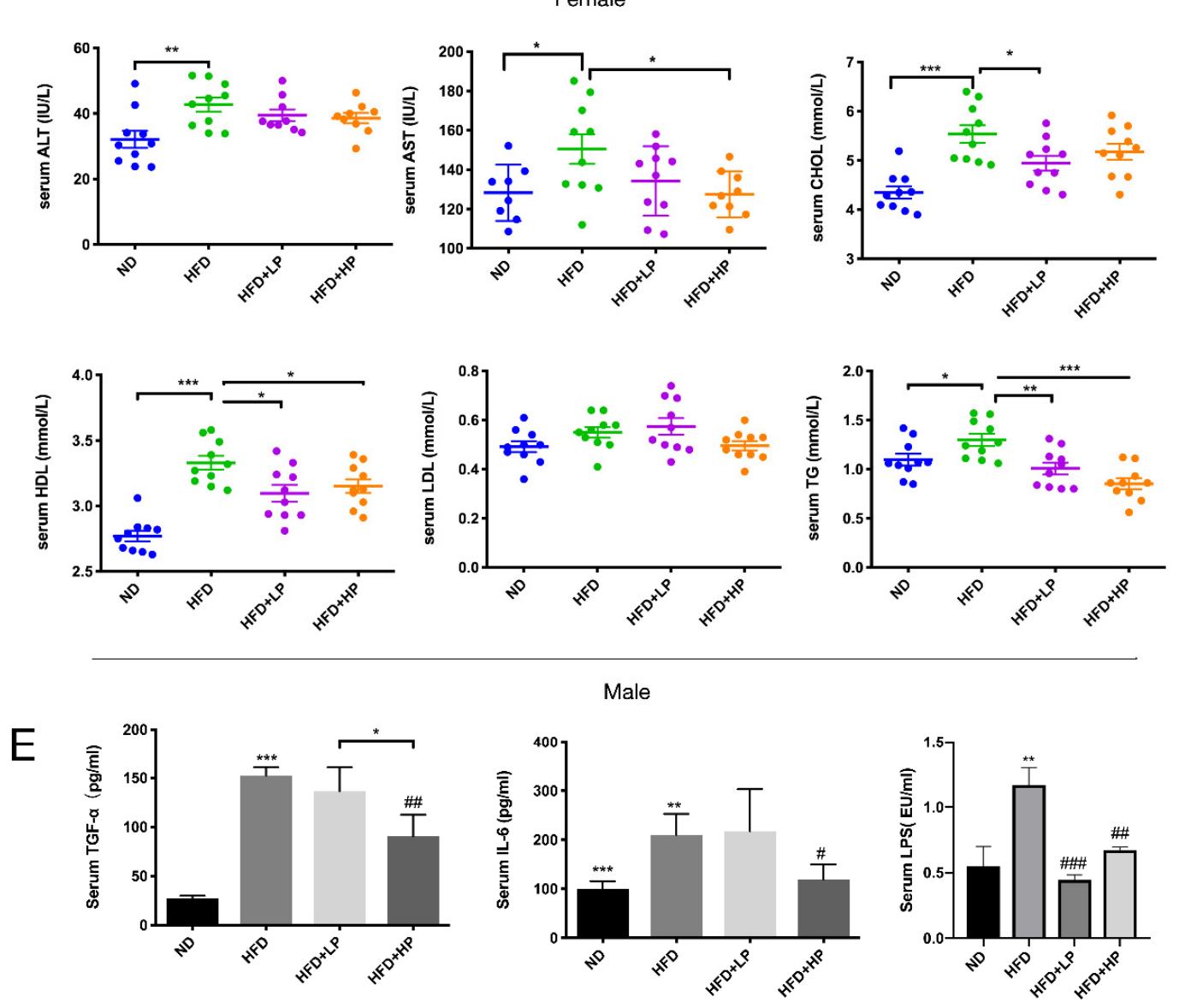

Female
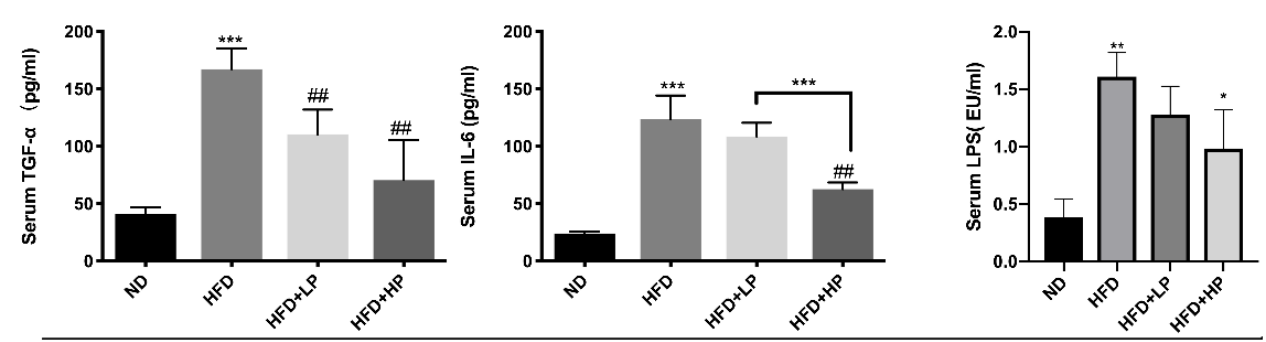

Male 
Figure 2. $\mathrm{CP}$ administration improved insulin sensitivity and lipid metabolism in HFD-fed mice. Oral glucose tolerance tests $(\mathbf{A})$ and insulin tolerance test $(\mathbf{B})(n=10)$ were measured in the 8 th and 9th week during the experiment, respectively. (C) Curves of blood glucose levels and the calculated area under curve (AUC) (inner graph). Values are expressed as the mean \pm SEM. (D) Serum concentrations of alanine aminotransferase (ALT), aspartate aminotransferase (AST), cholesterol (CHOL), high-density lipoprotein (HDL), low-density lipoprotein (LDL), and triglycerides (TGs) in mice $(n \geq 8)$. (E) Plasma concentrations of transforming growth factor alpha (TGF- $\alpha$ ), interleukin-6 (IL-6) and lipopolysaccharide (LPS) in mice. Values are presented as the mean \pm SEM.

\subsection{CP Prevented Liver Steatosis and Promoted Liver Lipid Metabolism in HFD-fed Mice}

Obesity is often accompanied with steatohepatitis [28]. CP treatment, even at a low concentration, effectively prevented lipid accumulation in liver tissue, demonstrable by Oil Red O staining in both female and male mice (Figure 3A). In addition, CP significantly $(p<0.005)$ reduced the liver weights of both female and male HFD-fed mice compared to controls. Further, HP reversed this in the male group ( $p<0.05$ ). The liver TG concentration also significantly declined, consistent with the beneficial effect of CP on liver steatosis (Figure 3B).

A

ND

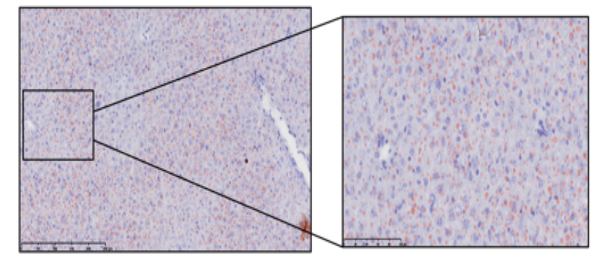

HFD

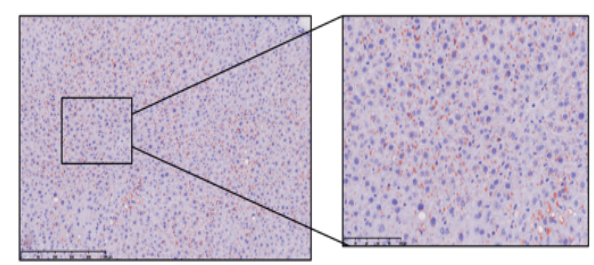

$\mathrm{HFD}+\mathrm{LP}$

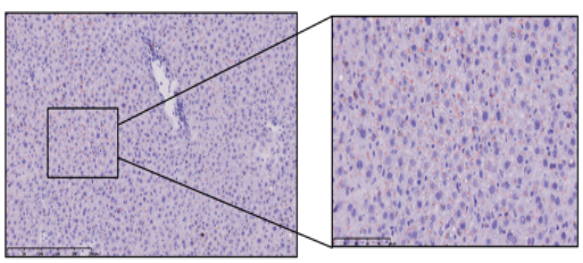

$\mathrm{HFD}+\mathrm{HP}$
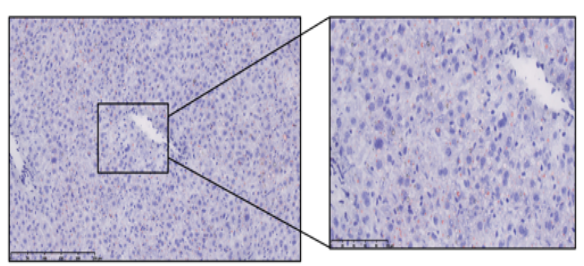

Male
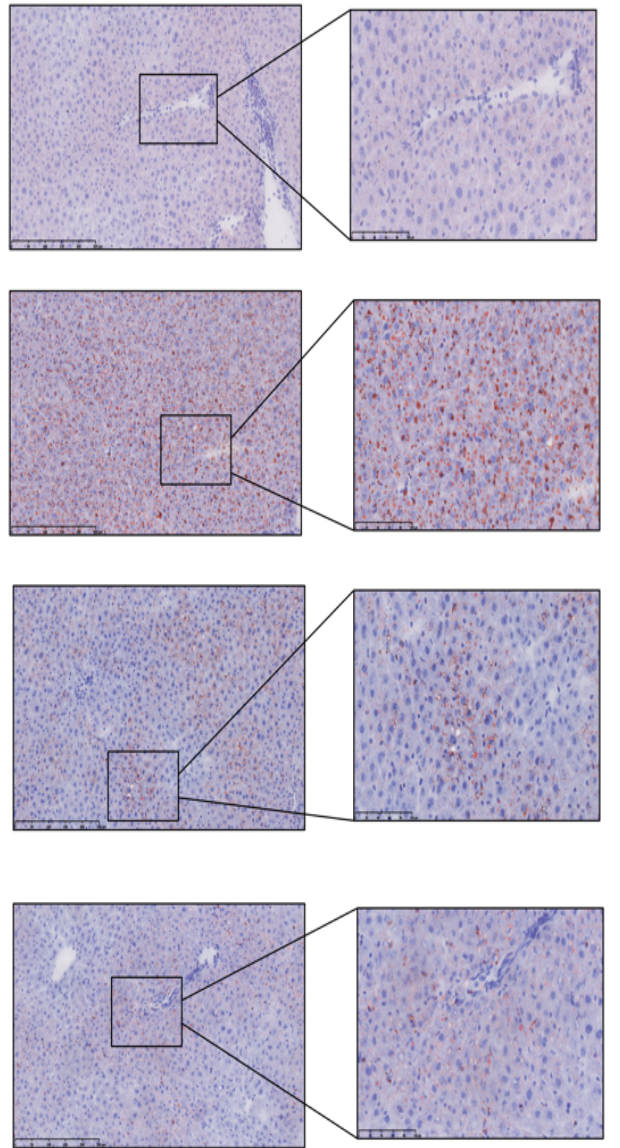

Figure 3. Cont. 

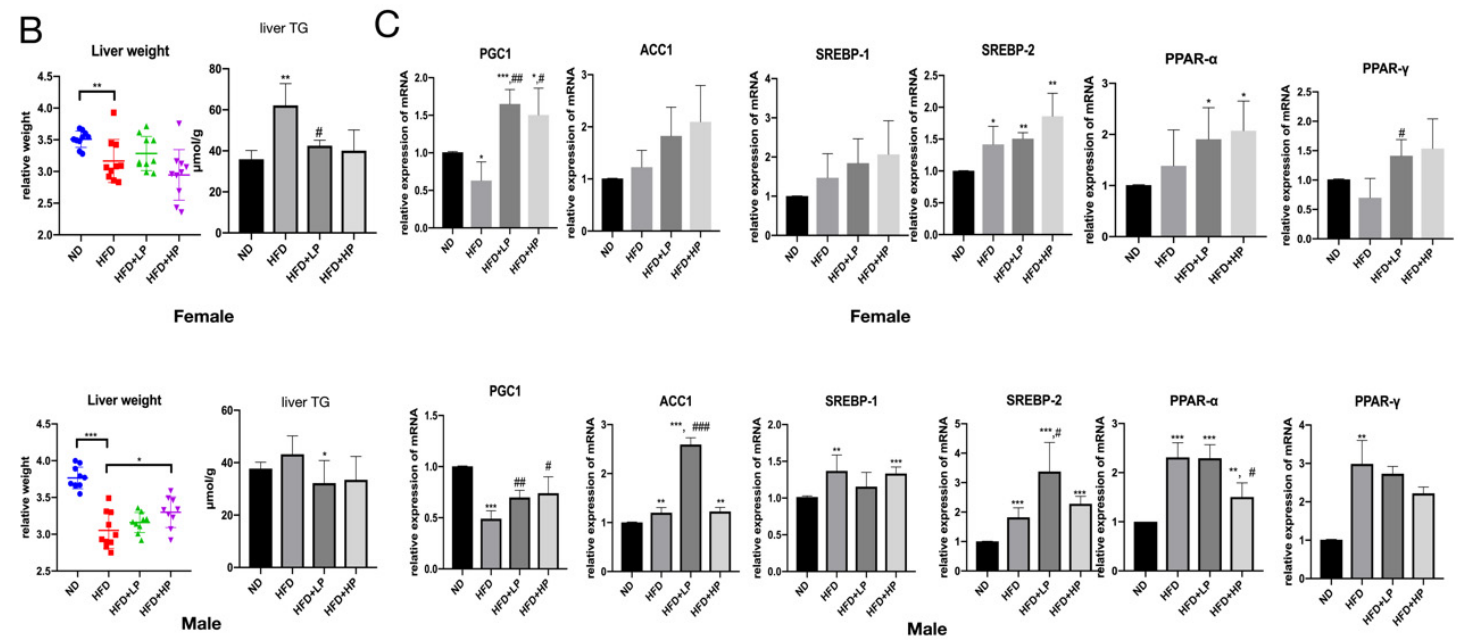

Figure 3. CP application prevented liver steatosis and promoted liver lipid metabolism in HFD-fed mice. (A) Liver Oil Red O staining of each group in both female and male mice. Each bar: $50 \mu \mathrm{m}$ in original photo; $20 \mu \mathrm{m}$ in enlarged photo. (B) Liver TG concentration and liver weight were changed according to the diet. (C) The relative expression of PGC1, ACC1, SREBP1/2, and PPARa/ $\gamma$ mRNA in liver, and were normalized with $\operatorname{GADPH}(n=8)$. Values are presented as the mean $\pm \mathrm{SD}$.

To examine the molecular pathways that regulate lipid metabolism, we measured mRNA expression of lipid metabolism-related genes in liver, including PGC1, ACC1, PPARa $/ \gamma$ and SREBP1/2 (Figure 3C). HFD markedly enhanced the relative mRNA expression of $A C C 1, P P A R \alpha / \gamma$, and SREBP1/2, and reduced the expression of PGC1 significantly in male mice. In female mice, only PGC1 and SREBP2 was regulated significantly by HFD. HP treatment restored PGC1 expression in both female and male mice, and significantly decreased the PPAR- $\alpha$ level in male mice.

\subsection{CP Promotes Browning of Adipose Tissue in HFD-fed Mice}

HFD enhanced the lipid accumulation in mice, which is considered as "whitening" of the BAT, especially in male mice (Figure 4A), while CP treatment (LP and HP) successfully reversed the lipid accumulation and stimulated the growth of BAT ("browning"). HFD increased the size of adipocyte cells collected from Epi-WAT and Par-WAT section (Figure 4C), while the size remained similar to the ND group and propolis-fed groups. Hence, we examined the mRNA expression levels of mitochondrial biogenesis (PGC1 $\alpha)$, energy expenditure (DIO2), fatty acid catabolism (CPT1 $\beta)$, lipid transport (CD36 and $F A B P$ ) and thermogenic genes (UCP1 and $U C P 3)$ in BAT. As shown in Figure $4 \mathrm{~B}$, all genes were elevated significantly in HFD-fed male mice, while only CD36, UCP1 and UCP3 increased in female mice. Oral administration with $\mathrm{CP}$ increased all the markers expression levels compared to the ND group, regardless of gender, and the $\mathrm{CP}$ supplementation group had higher levels of $C P T 1 \beta, D I O 2$, $F A B P, P G C 1$ and $U C P 1 / 3$ in comparison to the HFD group in female mice $(p<0.05)$. In male mice, only DIO2 expression level was significantly elevated in CP administration group compared to the HFD-fed group. We observed no differences in CD36, FABP, PGC1 and UCP1/3 expression levels. Collectively, these results demonstrated that $\mathrm{CP}$ stimulates $\mathrm{BAT}$ browning and thermogenesis in HFD-induced obese mice. 
A
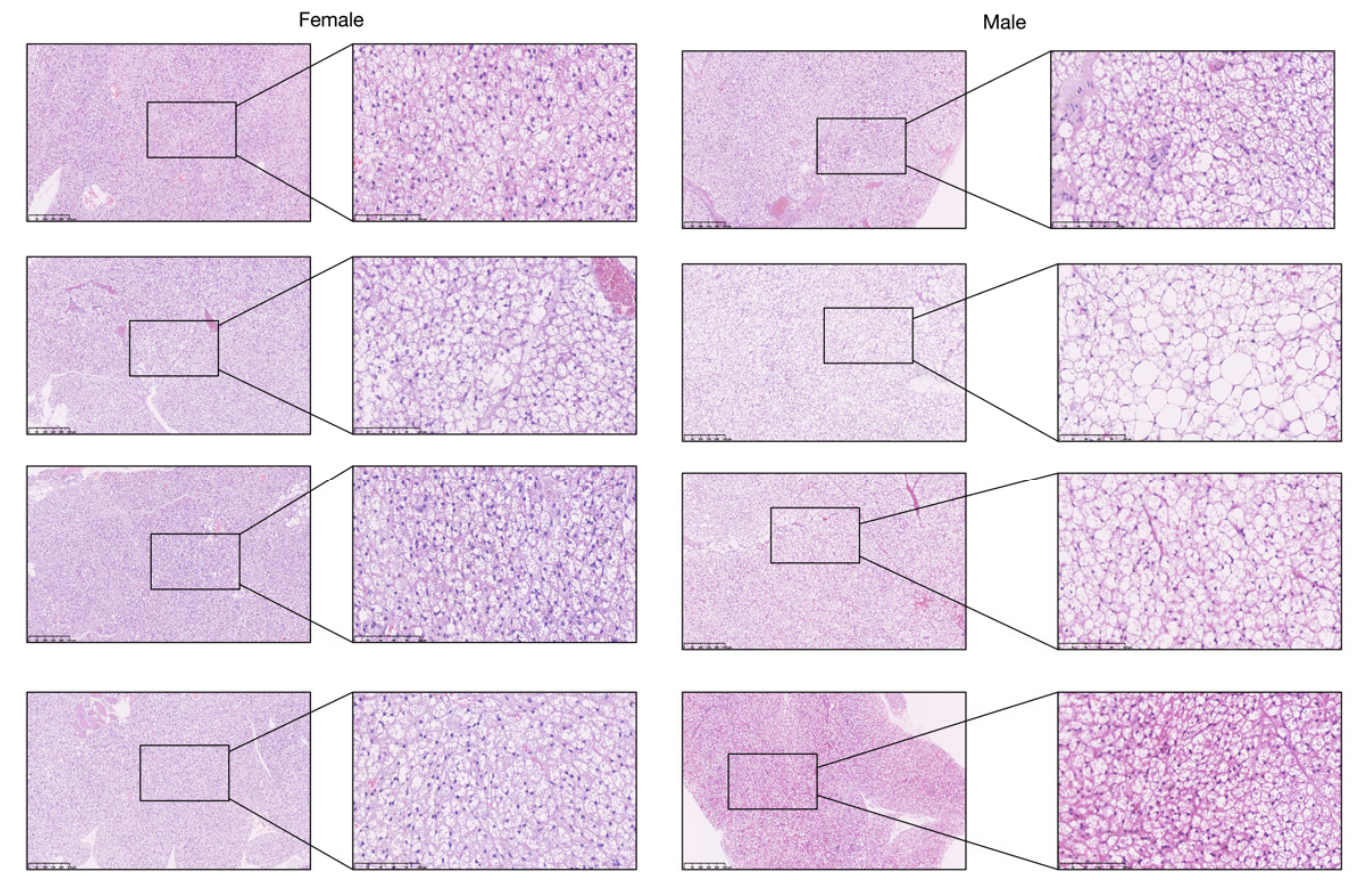

B
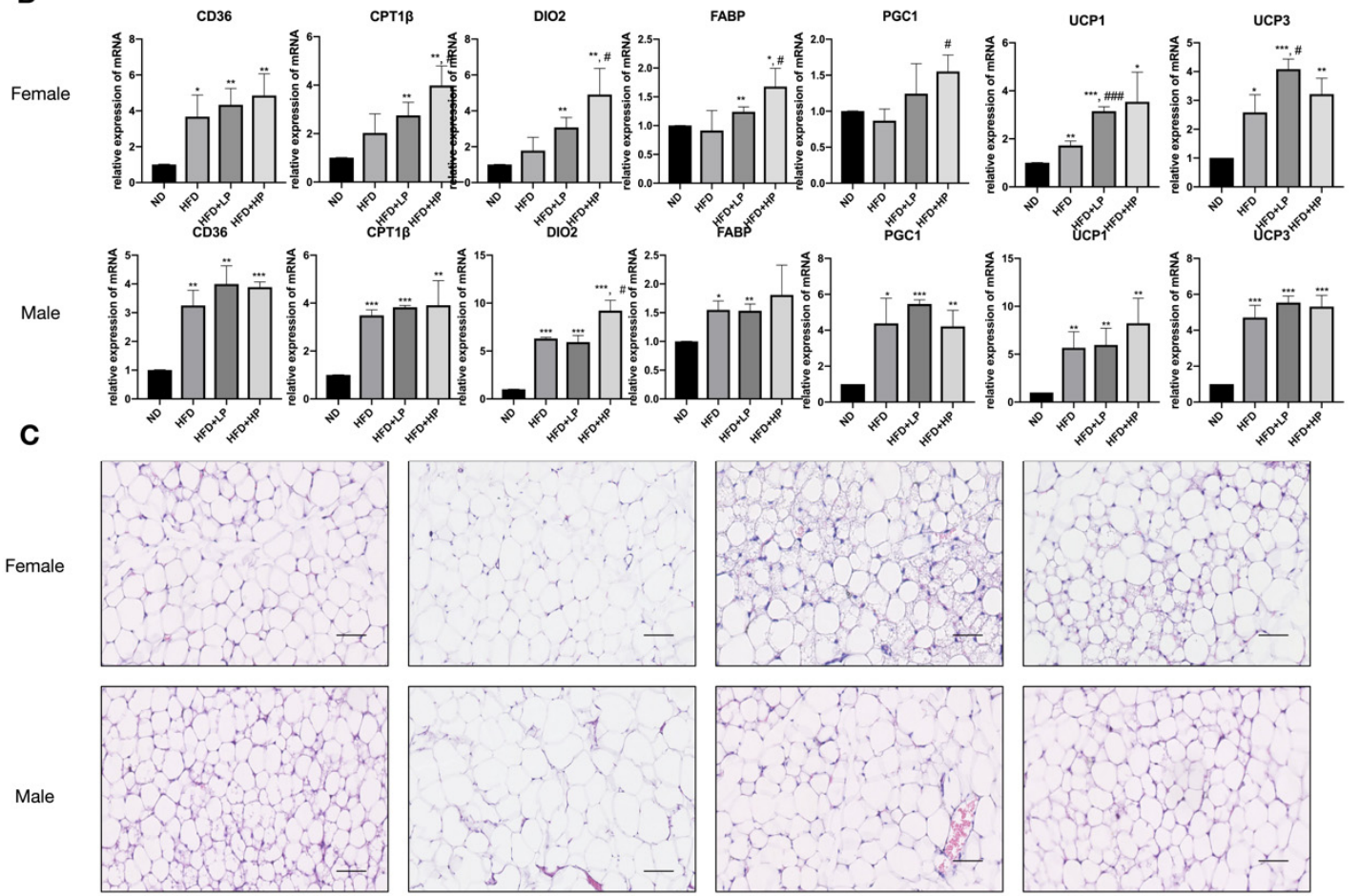

Figure 4. Effects of CP on adipose tissue (BAT \& WAT) formation in HFD-fed mice. (A) Hematoxylin and eosin (H\&E) staining of brown adipose tissue section. Each bar: $50 \mu \mathrm{m}$ in original photo; $20 \mu \mathrm{m}$ in enlarged photo. (B) The relative mRNA expression of adipose browning-related genes $(C D 36, C P T 1 \beta$, DIO2, FABP, PGC1, UCP1, and UCP3) in BAT. (C) H\&E staining of epididymal and parametrial white adipose tissue sections. Scale: $100 \mu \mathrm{m}$. 


\subsection{The Effects of CP on Gut Microbiota Alteration}

Recent research has revealed the interaction between gut microbiota and obesity [21]. Thus, we determined whether the anti-obesity effect of $\mathrm{CP}$ modulates gut microbiota by sequencing the bacterial $16 \mathrm{~S}$ rRNA V3 + V4 region. In female mice, a total of 3,076,876 raw reads were collected from 40 stool samples, and 2,895,343 clean reads were assessed after quality filtering, with an average of 72,383 per mouse. In male mice, a total of 3,334,760 raw reads were collected from 40 stool samples, and 3,144,620 clean reads were assessed after quality filtering, with an average of 78,616 per mouse. Microbial diversity differed among the ND, HFD, HFD+LP and HFD+HP groups (Figure 5). Interestingly, changes in the alpha diversities of gut microbiota differed by gender according to the rarefaction and rank curves (Figure 5A). In female mice, HFD reduced the alpha diversity of intestinal microbiota. In contrast, in male mice, HFD increased the alpha diversity of intestinal microbiota. In both genders, a low concentration of $\mathrm{CP}$ administration failed to influence the microbiota diversity, while a high concentration of $\mathrm{CP}$ reversed the change made by HFD in both female and male mice. We also calculated the Shannon, Chao 1, Simpson, and ACE indexes. Consistent with the number of operational taxonomic units (OTUs), a high concentration of $\mathrm{CP}$ significantly increased the richness and diversity of gut microbiota in female HFD-fed mice, but had the opposite effect in male mice. In order to investigate the structural changes in intestinal microbiota, we used non-metric multidimensional scaling (NMDS), principal coordinate analysis (PCoA), and principal component analysis (PCA). Based on PCoA and NMDS results, there was a distinct clustering of gut microbiota within different diet groups in both female and male mice.

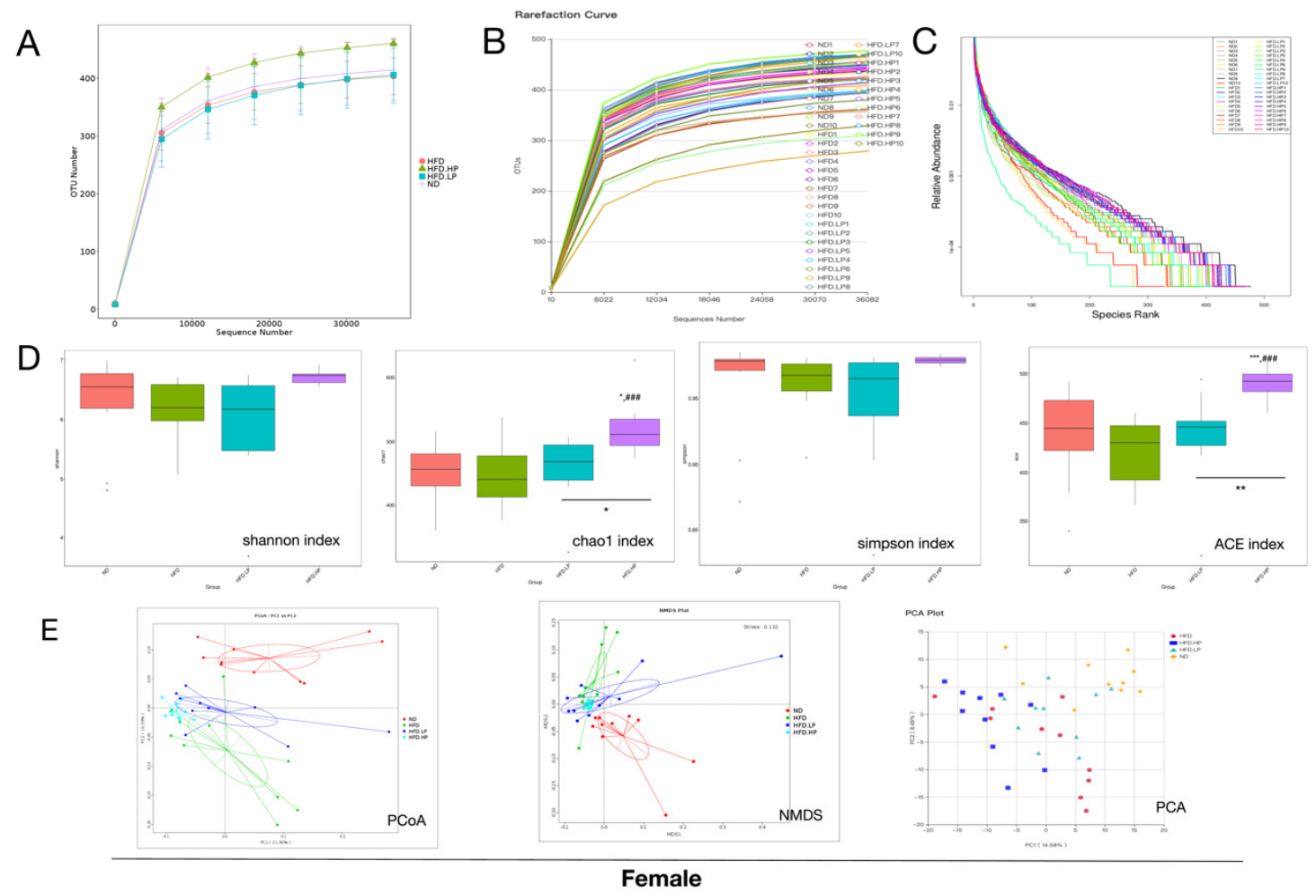

Figure 5. Cont. 


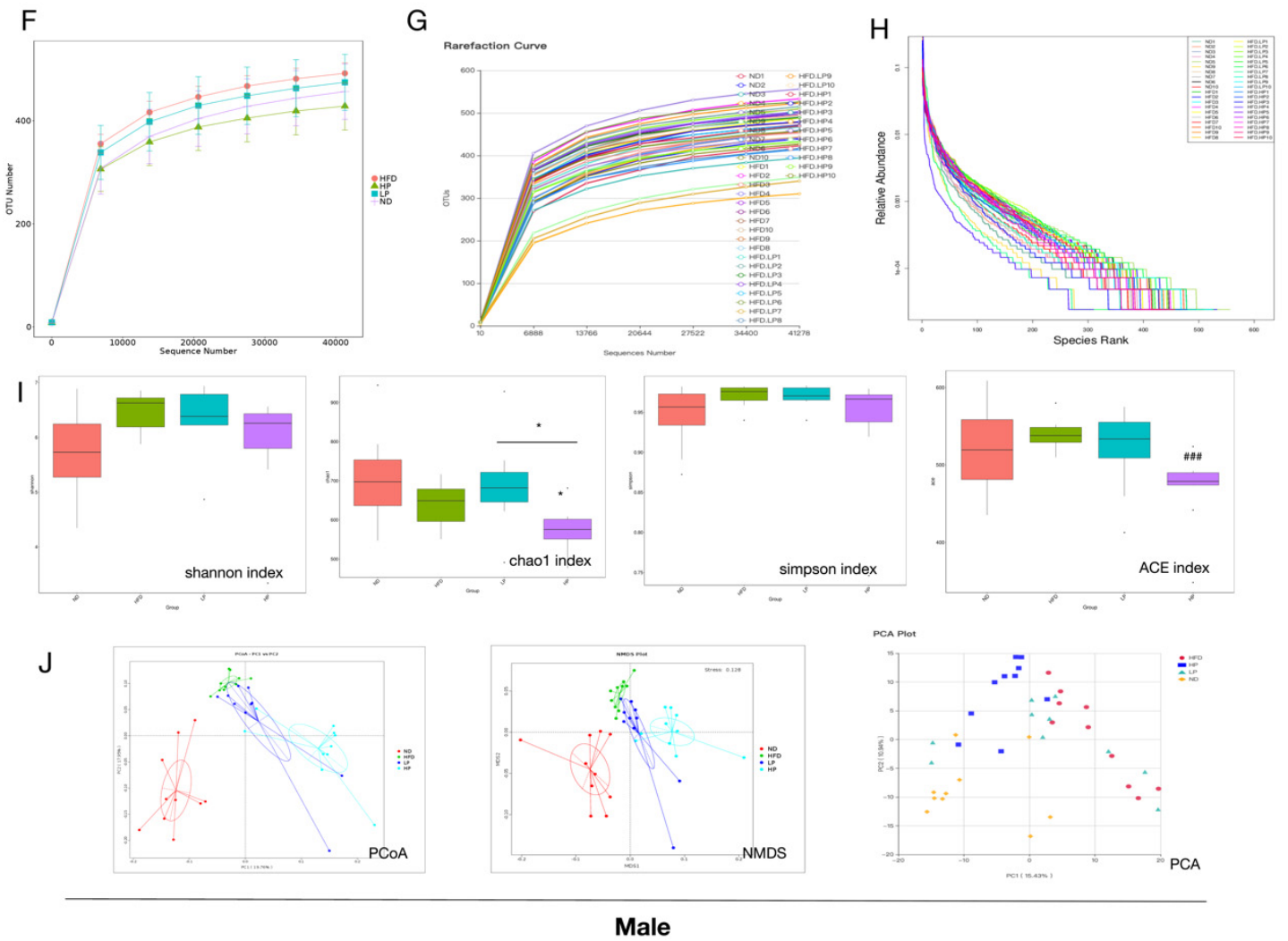

Figure 5. $\mathrm{CP}$ application altered microbial diversity and structure in HFD-fed mice. The operational taxonomic unit (OTU) rarefaction curve and the rank curve of microbial diversity responded to dietary change and CP treatment in female mice $(\mathbf{A}-\mathbf{C})$ and male mice $(\mathbf{F}-\mathbf{H}) .(\mathbf{D}, \mathbf{I})$ show the Shannon, Chao1, Simpson and ACE indexes in both genders. (E,J) Principal coordinate analysis PCoA score plot based on a binary Jaccard, non-metric multidimensional scaling (NMDS) score plot based on an unweighted, and principal component analysis (PCA) score plot based on weights.

\subsection{Relative Abundance of Gut Microbiota Changes in Response to HFD and CP Treatment}

Previous research has demonstrated that obesity is accompanied by changes in gut microbiota structure [17]. At the phylum level, Bacteroidetes was increased, while Firmicutes was reduced in the HFD group of either gender. However, there was a difference between female and male mice at the genus level. In female mice, the HFD group had a higher level of Lactobacillus (Figure 6A,B). In contrast, Lactobacillus was down-regulated significantly in male HFD-fed mice (Figure 6F,G), and ingestion of $\mathrm{CP}$ restored the level of Lactobacillus in male mice even in the LP group. In contrast, the changes in Lactobacillus in female mice induced by HFD were only reversed in the HP group. A similar trend was observed in Alistipes in both female and male mice. HFD increased Alistipes, and CP reversed the trend in a dose-dependent manner. Except for the bacteria mentioned above, the levels of Bacteroides were also abundant in the HFD groups of both genders.

We also used Linear discriminant analysis effect size (LEfSe) to identify the taxa associated with obesity and $\mathrm{CP}$ treatment. A total of 12 taxa in female and 18 taxa in male showed significant differences in the relative abundance among the ND-, HFD- and HP-treated groups (Figure 6C-E,H-J). In both genders, the ND group had more bacterial class Erysipelotrichia, whereas the HFD group had more Deltaproteobacteria. In female mice, the families Rikeneliaceae, Desulfovibrionaceae and Helicobacteraceae were also more abundant in the HFD group than the ND group. In the HP group, the families Bacteroidaceae and Lachnospiraceae were increased compared to the HFD group. Interestingly, male mice fed HP also had increased Bacteroidaceae. 
Female

A

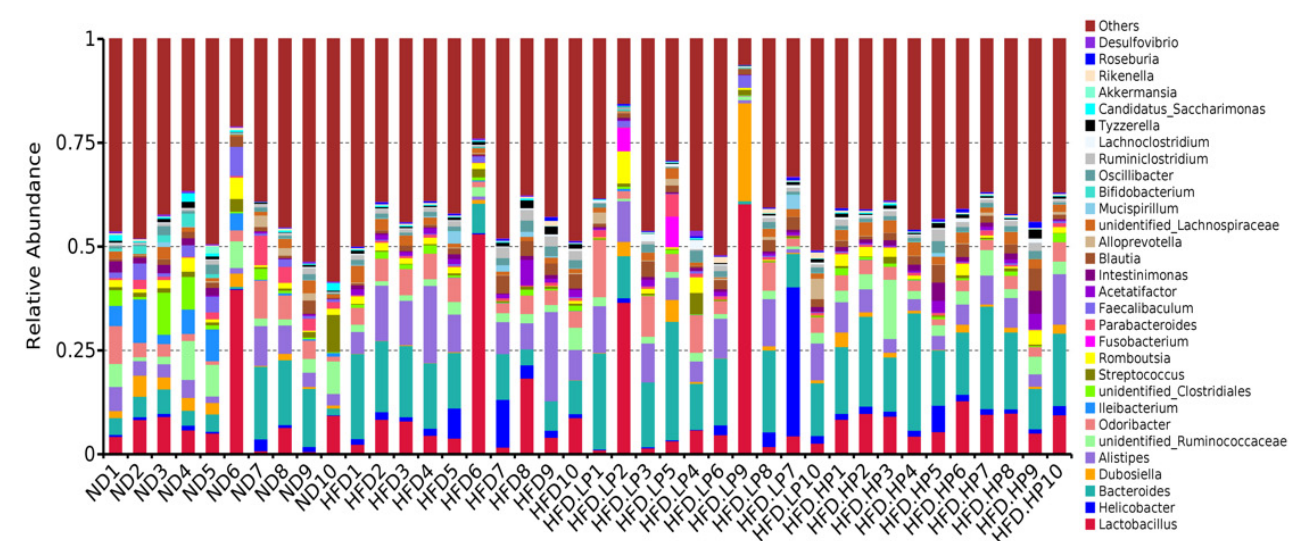

Sample Name

B

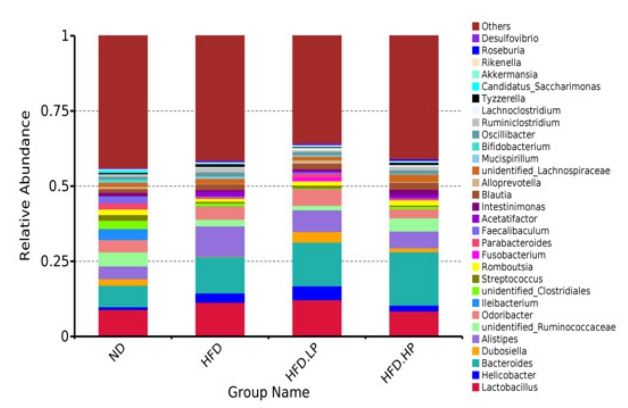

D

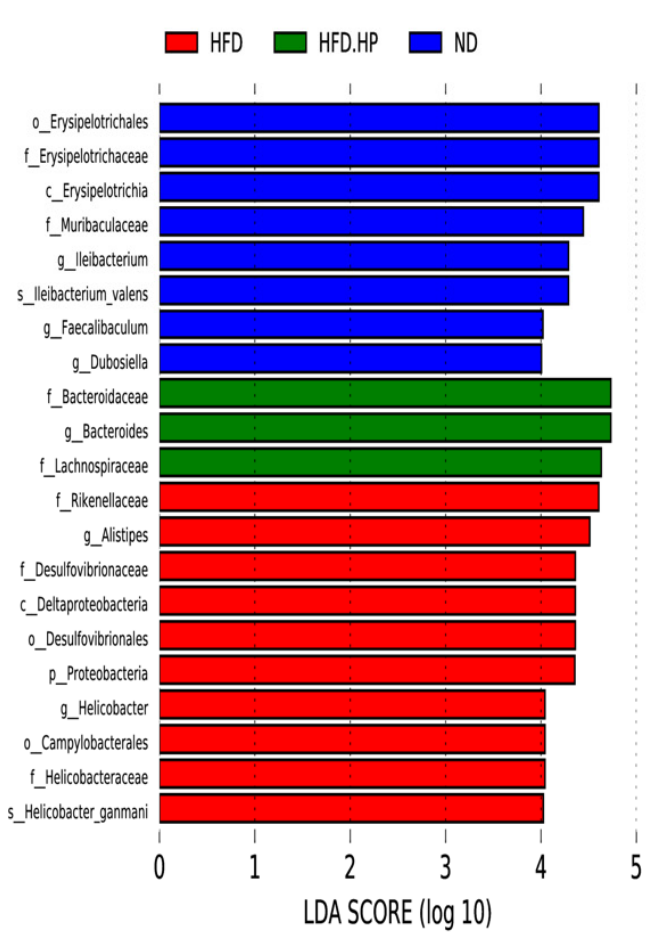

C
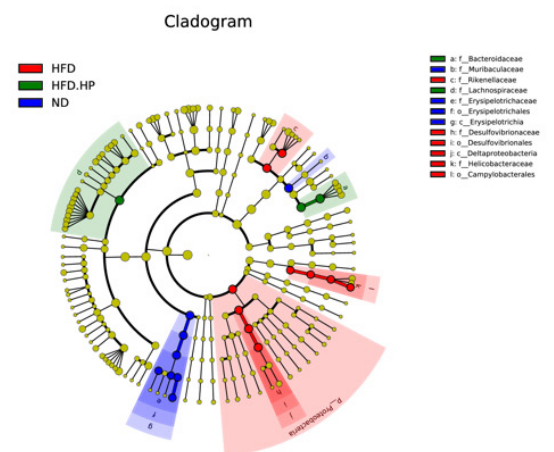

E

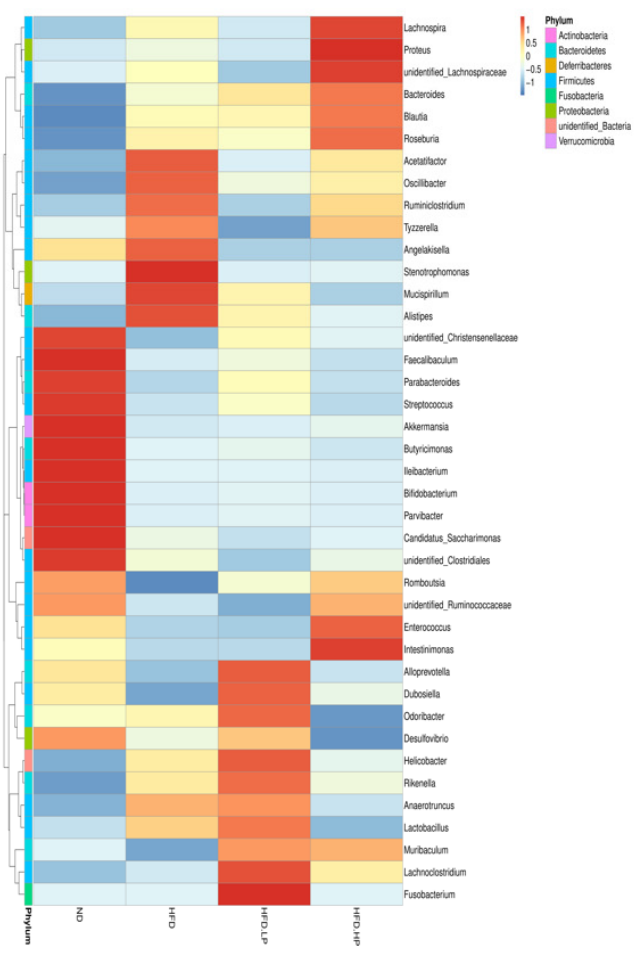

Figure 6. Cont. 


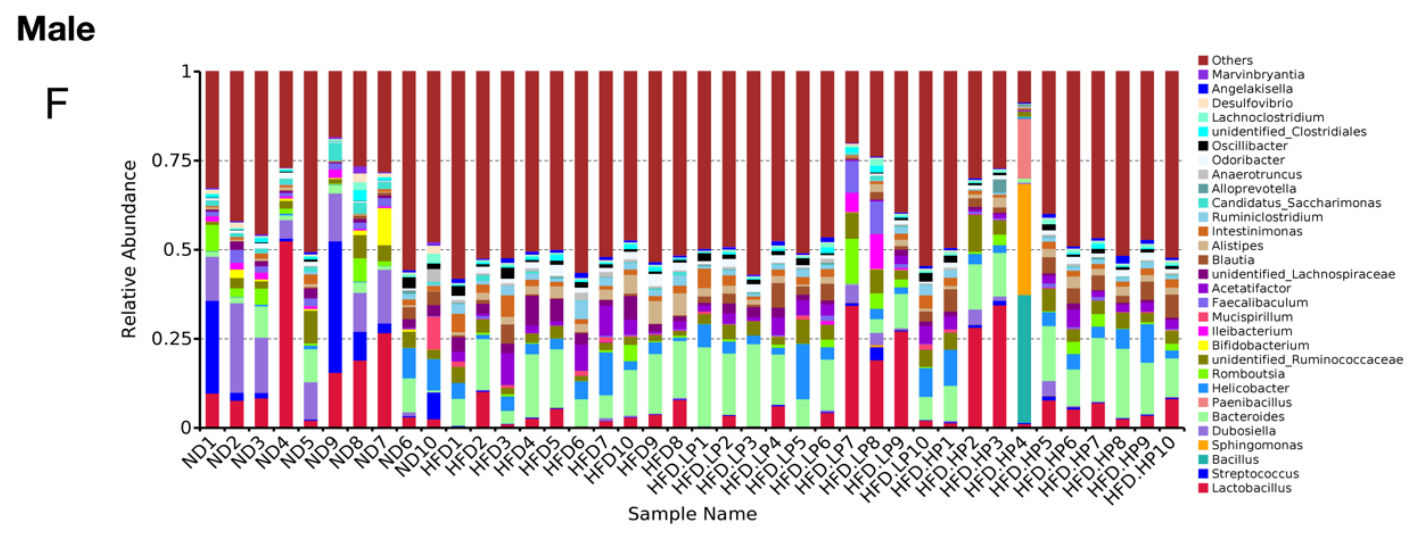

$\mathrm{G}$

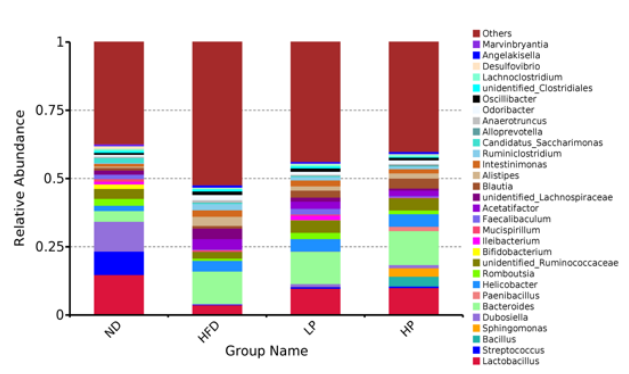

$\mathrm{H}$
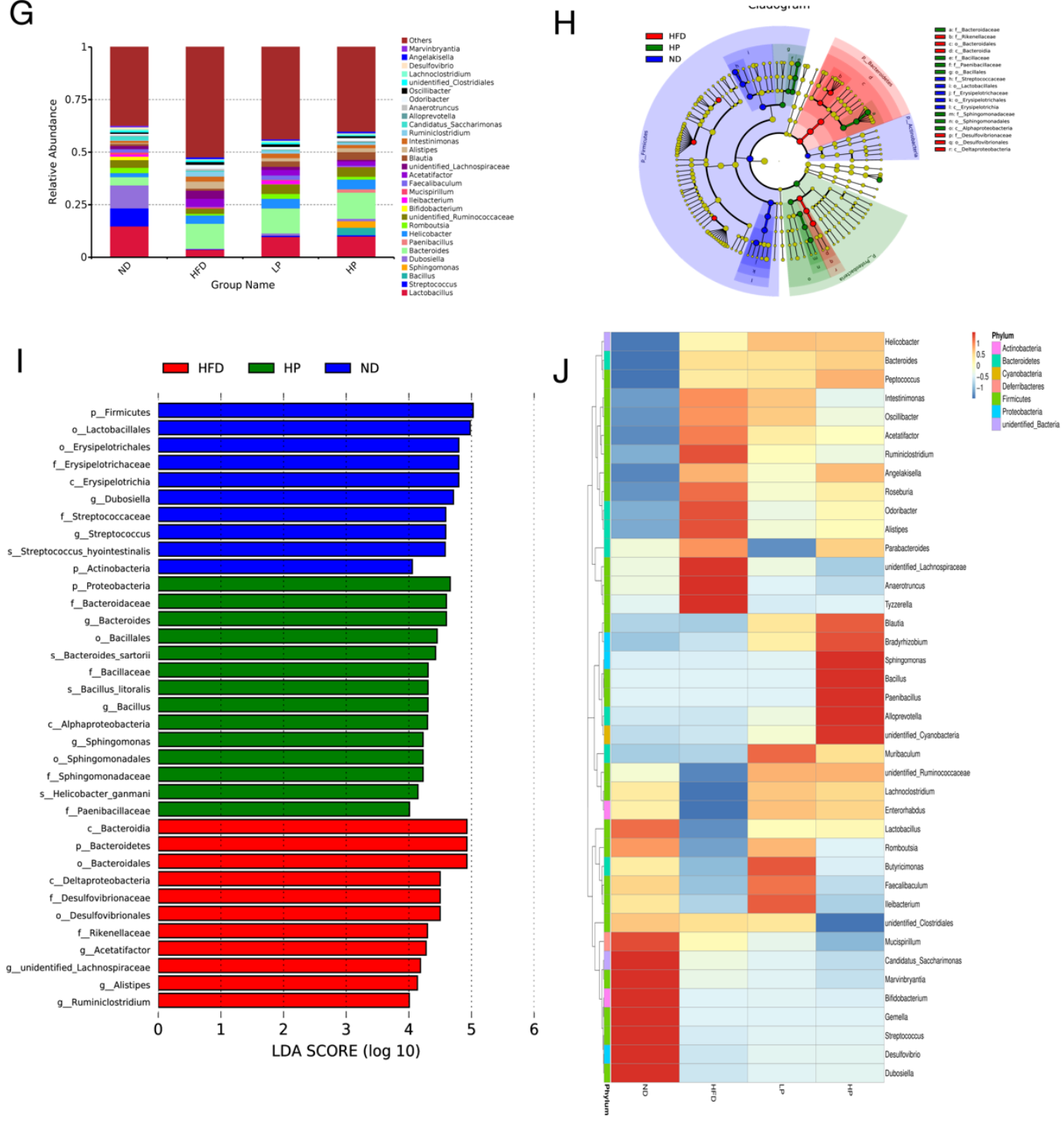

Figure 6. Differences in the bacterial community induced by diet and treatment according to the relative abundances of gut microbiota at the genus level and LEfSe analysis. (A,B,F,G) The relative abundance of intestinal microbiota at the genus level in the four groups of both genders. (C,D,H,I) LEfSe results showed the change in microbiota under HFD and HP administration. The LDA significant threshold was 4.0. Red, green, and blue represented HFD, HP, ND, respectively. (E,J) Heat maps of taxons that were most significantly different in abundance between the four groups at the genus level generated by LEfSe analysis. 


\subsection{Effects of CP on SCFA Production}

To further examine the effect of CP on gut health, we analyzed short-chain fatty acid (SCFA) concentration in the colon, including acetic acid, propionic acid, isobutyric acid, butanoic acid and isovaleric acid. Acetic acid and propionic acid were the two most abundant SCFAs in both genders, while other acids were present at less than $0.01 \mathrm{mg} / \mathrm{g}$ (data not shown). There was no significant change in acetic acid and propionic acid among groups in female mice, while acetic acid was reduced significantly in the HFD group in male mice. HP treatment showed a trend towards an increase in the concentration of acetic acid in male mice. Concentrations of propionic acid were also unaffected by HFD in male mice. Interestingly, the HP group showed the highest level of propionic acid among all the groups (Figure 7).

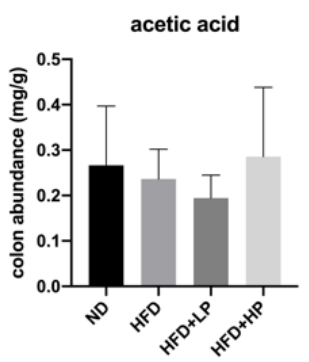

Female

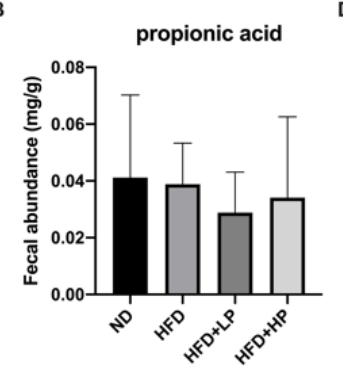

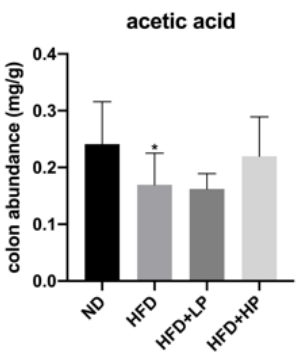

Male

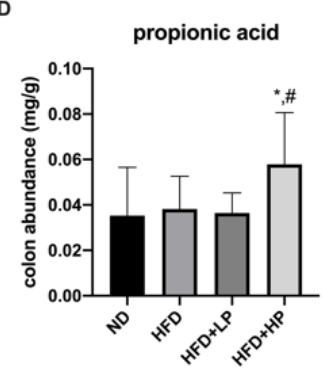

Figure 7. The modulation of main colon short-chain fatty acid (SCFA) concentrations responded to HFD and CP administration in female mice $(\mathbf{A}, \mathbf{B})$ and male mice $(\mathbf{C}, \mathbf{D})$. Data are presented as the mean \pm SD.

\section{Discussion}

The increasing incidence of obesity poses a great threat to public health worldwide. The close association between obesity and multiple diseases contributes to increased morbidity and mortality [7,29]. Given that the consumption of plant-derived foods rich in polyphenols has positive effects on protecting against metabolic syndromes, these foods have been tested on obesity models $[9,10]$. Here, we studied the impact of CP on obesity development including glucose tolerance, lipid accumulation and gut microbiota alteration in both female and male mice models.

We found that CP administration prevented HFD-induced weight gain and fat mass accumulation in both female and male mice. Brown adipose tissue is characterized as a site for adaptive thermogenesis activated by the sympathetic nervous system, which is believed to be artificially induced [30]. In our study, CP administration reversed the "whitening" process induced by HFD in BAT and increased the expression of UCP1 and UCP3 in both female and male mice. These results suggest that CP can boost thermogenesis by promoting lipid metabolism and BAT growth in HFD-induced obese mice.

Furthermore, propolis prevented lipid accumulation and serum TG metabolism in male mice, although no significant difference was found in female mice. CP also improved glucose tolerance and insulin resistance in HFD-fed mice of both genders. The is consistent with previous studies reporting 
that dietary propolis can improve insulin sensitivity in the early stage of insulin resistance developed in different mice models [31-33], suggesting that the effect of propolis on glucose control is universal.

Accumulating evidence has suggested that gut microbiota play a significant role in disease development, including obesity, type 2 diabetes, and cancers $[17,20,34]$. Given that much still remains unknown about the process of phenolic phytochemical absorption after ingestion, it has been proposed that it may act primarily via the intestine $[35,36]$. Our results showed that HFD induced a shift in gut microbiota of mice. Interestingly, HFD was reported to increase the ratio of Firmicutes and Bacteriodetes in other studies [37,38], while lower Firmicutes and Bacteriodetes ratios were found in the HFD groups in mice of both genders in the present study. It should be noted that Schwiertz et al. also reported lower ratios of Firmicutes and Bacteriodetes in obese people [39]. Since the development of obesity and metabolic disorders is a complex process involving genetic and environmental factors, the genetic background of animal models and formations of forage potentially influence components of the gut microbiome. Furthermore, Arumugam et al. demonstrated that enterotypes in the human gut microbiome are more accurate, indicating that studies should not only focus at the phylum level [40]. Therefore, we also examined microbiota modulation at the genus level. Alistipes, a genus in the phylum Bacteroidetes, has been found to be abundant in humans with type 2 diabetes and obesity [22,41]. In our study, Alistipes increased significantly in both female and male HFD-fed mice. This was consistent with the uptrend of Bacteroidetes at the phylum level. Another genus that we addressed was the beneficial bacteria Ruminococcaceae, which decreased significantly in HFD-fed mice. Ruminococcaceae is one of the most abundant Firmicute families in the gut environment and is primarily responsible for digesting polysaccharides and fibers [42,43]. Its low concentration is positively related to NAFLD and increases intestinal permeability [44,45]. CP application was found to stimulate Ruminococcaceae growth, evidenced by an increasing abundance and thicker intestinal mucosa (Figure S1). This result suggests that CP ingestion was able to reverse the trend induced by HFD and improve gut microbiome structure in a dose-dependent manner, helping to improve intestinal health.

Chronic low-grade systemic inflammation is increasingly being recognized for playing a role in glucose, lipid metabolism in the early stage of type 2 diabetes and obesity pathogenesis [27,46]. It was also reported that inflammation contributes to NAFLD progression via elevated endotoxin levels [47]. Studies have revealed that infusion with LPS, known as endotoxins, elicited a similar inflammatory response as HFD in animals [48]. In the present study, CP gavage showed great ability to prevent NAFLD by reducing liver lipid accumulation and alleviating hepatic inflammation, which we believe is associated with the great capacity of $\mathrm{CP}$ to scavenge free radicals. Additionally, $\mathrm{CP}$ gavage reduced the LPS concentration significantly, as well as the circulating IL-6, IL-10 and TGF $\alpha$ concentration, demonstrating its anti-inflammatory effect in HFD. LPS and associated inflammatory molecules will spread into the bloodstream when gut permeability is modulated $[48,49]$. Further, the circulating LPS is mainly derived from Gram-negative bacteria in the intestinal ecosystem. In our study, Alistipes, the main producer of LPS, were found to be increased in HFD mice. However, CP ingestion reversed this increase. Furthermore, given that probiotic Lactobacillus alleviates LPS-induced inflammation and decreases TGF $\alpha$ level in vivo and in vitro [50-53], it is suggested that the increasing Lactobacillus may play a role in CP suppressing LPS-induced inflammation. Another researcher has pointed out that patients under an inflammatory environment usually had an increased TG level [54], which was in agreement with our result. The CP gavage effectively promoted TG metabolism in male mice $(p<0.05)$. Collectively, these results indicated that $\mathrm{CP}$ exerted a protective effect on the intestine by reducing Alistipes abundance, leading to lower inflammation and endotoxin levels in vivo.

In addition to establishing the intestinal environment, gut microbiota also stimulates epithelial regeneration by producing short-chain fatty acids (SCFAs) [55]. Interestingly, Lactobacillus, Bacteroides and Alistipes - all of which changed in this study-belong to acetic acid-producing genera. Yin et al. reported that there is a marked correlation between acetic acid production and Bacteroides, as well as Alistipes relative abundance [56]. In this study, HFD reduced acetic acid levels in colons, especially in male mice $(p<0.05)$. Further, HP application seemed to upregulate acetic acid levels, although 
there is no statistical significance between the two. We assumed that the modulation of intestinal microbiota induced by CP may also have an impact on SCFAs. Further experiments could be carried out to determine the interplay between SCFAs and CP administration.

Previous studies have proposed that sex could influence the efficacy of drugs [37,57], and experiments limited in male mice may not be able to provide thorough information about the function of drugs. In our study, we noticed that the composition of gut microbiota completely changed in HFD diet-fed male mice while the main microbiota remained similar in female mice. We also found that the anti-obesity effect of $\mathrm{CP}$ was gender related. Male mice were determined to be more sensitive to the $\mathrm{CP}$ treatment, as revealed by a lower working concentration of $\mathrm{CP}$. As for the fat development induced by HFD, CP shows better performance in male mice than female mice according to the metabolic parameters and fat mass data (Figures 1 and 2B). Gelineau et al. has put forward that female mice were more resistant to HFD-induced physiological changes, showing lower levels of insulin secretion and better glucose tolerance in comparison to male mice, which may provide an explanation for our result [58]. Adipose tissue is also known to express and secrete a variety of metabolites, hormones, and cytokines that have been implicated in the development of insulin resistance and glucose tolerance [29,59]. As expected, CP improved post glucose hyperinsulinemia in both female and male HFD-fed mice, which is supported by a lower fasting glucose level and thus HOMA-IR index. However, CP failed to improve insulin resistance in female mice. We also found that Lactobacillus showed the opposite trend in female and male HFD-fed mice. Although diet is believed to be the primary factor driving gut microbial changes, there is still evidence that these changes are sex dependent $[60,61]$. In a previous study, the probiotic strain Lactobacillus was proven to benefit intestinal immunity [62]. Its strains, Lactobacillus johnsonii La1 and Lactobacillus gasseri BNR17, can prevent weight gain under HFD and improve insulin sensitivity [51,63]. These findings were perfectly consistent with the changes in male mice. Further, we found that $\mathrm{CP}$ obviously restored the Lactobacillus level in HFD-fed male mice at both low and high concentrations. In contrast to male mice, Lactobacillus slightly increased in female HFD-fed mice, differing from previous studies. However, it should be noted that all previous studies about Lactobacillus only analyzed male mice. Additionally, Lee et al. discovered that the composition of vaginal microbiota is altered significantly by menopausal status, suggesting the composition of the human vaginal microbiota is highly associated with hormone levels [64]. Interestingly, recent studies have uncovered an interaction between estrogens and the microbiome that may affect metabolic rate, body weight, and adiposity [65]. E2 treatment could regulate the inflammation induced by HFD and increase the thickness and keratinization of epithelia [66]. Polyphenols were reported as ligands of estrogen receptors (ERs) due to their ER binding affinity, and are able to target hormone-related cancers [67]. Furthermore, emerging evidence shows that propolis has an estrogenic effect through activation of ERs [68,69]. Therefore, our results for female mice may support the idea that the microbiota is affected by the hormone status of the mice, especially by estrogen. Further experiments could be conducted to investigate the relation between estrogen level and CP treatment in HFD-fed mice. Collectively, our study indicated that the microbiota changes in HFD were sex dependent, and the mechanism underlying the anti-obesity effect of CP may be related to different hormone levels in female and male mice.

\section{Conclusions}

In summary, we reported for the first time that $\mathrm{CP}$ treatment could alleviate HFD-induced obesity. This effect was proven by less weight gain, better insulin sensitivity, and lower levels of metabolic endotoxemia, liver steatosis, and systemic inflammation. Furthermore, CP administration modulated gut microbiota by decreasing Alistipes abundance, regardless of gender, and increasing Lactobacillus in male mice. We believe that these two bacteria are playing an important role in the preventive effect of $\mathrm{CP}$ on obesity and type 2 diabetes. In addition, our results also support the theory that the composition of gut microbiota and responses to drugs differ by sex [37]. The effect of CP is more obvious in male mice, as compared to female mice. Collectively, Chinese propolis, which is rich in polyphenols, may 
prevent obesity and metabolic syndromes induced by diet, indicating the possibility of using $\mathrm{CP}$ as an alternative method for weight control.

Supplementary Materials: The following are available online at http://www.mdpi.com/2072-6643/12/4/959/s1, Table S1: The components identified in CP, Table S2: The primers we use in this study, Figure S1: H \& E-stained colon sections.

Author Contributions: Y.Z.: conceptualization, methodology, validation, formal analysis, investigation, data curation, writing-original draft; Y.W.: conceptualization, validation, formal analysis, investigation, data curation, writing-review\&editing; L.T.: validation, investigation; X.C.: validation, investigation; T.J.J.: Writing-review; K.W.: Writing-review; F.H.: supervision, project administration, funding acquisition, conceptualization, resources. All authors have read and agreed to the published version of the manuscript.

Acknowledgments: This study was supported by the National Natural Science Foundation of China (31902222, Y.W. and 31872431, F.H.), the Modern Agroindustry Technology Research System (CARS-44, F.H. and H.Z.), and a 2018 Zhejiang University Academic Award for Outstanding Doctoral Candidates.

Conflicts of Interest: The authors declare no conflict of interest.

\section{References}

1. The GBD 2015 Obesity Collaborators Health Effects of Overweight and Obesity in 195 Countries over 25 Years. N. Engl. J. Med. 2017, 377, 13-27.

2. Buettner, R.; Schölmerich, J.; Bollheimer, L.C. High-fat diets: Modeling the metabolic disorders of human obesity in rodents. Obesity (Silver Spring) 2007, 15, 798-808. [CrossRef] [PubMed]

3. Ikemoto, S.; Takahashi, M.; Tsunoda, N.; Maruyama, K.; Itakura, H.; Ezaki, O. High-fat diet-induced hyperglycemia and obesity in mice: Differential effects of dietary oils. Metabolism 1996, 45, 1539-1546. [CrossRef]

4. Torres, S.J.; Nowson, C.A. Relationship between stress, eating behavior, and obesity. Nutrition 2007, 23, 887-894. [CrossRef]

5. Hales, C.M.; Fryar, C.D.; Carroll, M.D.; Freedman, D.S.; Ogden, C.L. Trends in Obesity and Severe Obesity Prevalence in US Youth and Adults by Sex and Age, 2007-2008 to 2015-2016. JAMA 2018, 319, 1723-1725. [CrossRef]

6. Smith, K.B.; Smith, M.S. Obesity Statistics. Prim. Care Clin. Off. Pract. 2016, 1-15. [CrossRef]

7. Hossain, P.; Kawar, B.; Nahas, M.E. Obesity and diabetes in the developing world-A growing challenge. N. Engl. J. Med. 2007, 356, 213-215. [CrossRef]

8. Chang, E.; Kim, C.Y. Natural Products and Obesity: A Focus on the Regulation of Mitotic Clonal Expansion during Adipogenesis. Molecules 2019, 24, 1157. [CrossRef]

9. Anhê, F.F.; Roy, D.; Pilon, G.; Dudonné, S.; Matamoros, S.; Varin, T.V.; Garofalo, C.; Moine, Q.; Desjardins, Y.; Levy, E.; et al. A polyphenol-rich cranberry extract protects from diet-induced obesity, insulin resistance and intestinal inflammation in association with increased Akkermansia spp. population in the gut microbiota of mice. Gut 2015, 64, 872-883. [CrossRef]

10. Lama, A.; Pirozzi, C.; Mollica, M.P.; Trinchese, G.; Di Guida, F.; Cavaliere, G.; Calignano, A.; Mattace Raso, G.; Berni Canani, R.; Meli, R. Polyphenol-rich virgin olive oil reduces insulin resistance and liver inflammation and improves mitochondrial dysfunction in high-fat diet fed rats. Mol. Nutr. Food Res. 2016, 61, 1600418-1600430. [CrossRef]

11. Sforcin, J.M.; Bankova, V. Propolis: Is there a potential for the development of new drugs? J. Ethnopharmacol. 2011, 133, 253-260. [CrossRef]

12. Chen, L.-H.; Chien, Y.-W.; Chang, M.-L.; Hou, C.-C.; Chan, C.-H.; Tang, H.-W.; Huang, H.-Y. Taiwanese Green Propolis Ethanol Extract Delays the Progression of Type 2 Diabetes Mellitus in Rats Treated with Streptozotocin/High-Fat Diet. Nutrients 2018, 10, 503. [CrossRef]

13. Koya-Miyata, S.; Arai, N.; Mizote, A.; Taniguchi, Y.; Ushio, S.; Iwaki, K.; Fukuda, S. Propolis prevents diet-induced hyperlipidemia and mitigates weight gain in diet-induced obesity in mice. Biol. Pharm. Bull. 2009, 32, 2022-2028. [CrossRef] [PubMed]

14. Fuliang, H.; Hepburn, H.; Xuan, H.; Chen, M.; Daya, S.; Radloff, S. Effects of propolis on blood glucose, blood lipid and free radicals in rats with diabetes mellitus. Pharmacol. Res. 2005, 51, 147-152. [CrossRef] 
15. Shin, S.H.; Seo, S.G.; Min, S.; Yang, H.; Lee, E.; Son, J.E.; Kwon, J.Y.; Yue, S.; Chung, M.-Y.; Kim, K.-H.; et al. Caffeic Acid Phenethyl Ester, a Major Component of Propolis, Suppresses High Fat Diet-Induced Obesity through Inhibiting Adipogenesis at the Mitotic Clonal Expansion Stage. J. Agric. Food Chem. 2014, 62, 4306-4312. [CrossRef] [PubMed]

16. Ley, R.E.; Turnbaugh, P.J.; Klein, S.; Gordon, J.I. Human gut microbes associated with obesity. Nature 2006, 444, 1022-1023. [CrossRef] [PubMed]

17. Tilg, H.; Kaser, A. Gut microbiome, obesity, and metabolic dysfunction. J. Clin. Investig. 2011, 121, $2126-2132$. [CrossRef]

18. Cani, P.D.; Bibiloni, R.; Knauf, C.; Waget, A.; Neyrinck, A.M.; Delzenne, N.M.; Burcelin, R. Changes in Gut Microbiota Control Metabolic Endotoxemia-Induced Inflammation in High-Fat Diet-Induced Obesity and Diabetes in Mice. Diabetes 2008, 57, 1470-1481. [CrossRef] [PubMed]

19. Everard, A.; Lazarevic, V.; Derrien, M.; Girard, M.; Muccioli, G.G.; Neyrinck, A.M.; Possemiers, S.; Van Holle, A.; François, P.; de Vos, W.M.; et al. Responses of Gut Microbiota and Glucose and Lipid Metabolism to Prebiotics in Genetic Obese and Diet-Induced Leptin-Resistant Mice. Diabetes 2011, 60, 2775-2786. [CrossRef] [PubMed]

20. Gérard, P. Gut microbiota and obesity. Cell. Mol. Life Sci. 2015, 1-16. [CrossRef] [PubMed]

21. Million, M.; Lagier, J.C.; Yahav, D.; Paul, M. Gut bacterial microbiota and obesity. Eur. Soc. Clin. Infect. Dis. 2014, 19, 305-313. [CrossRef] [PubMed]

22. Clarke, S.F.; Murphy, E.F.; O'Sullivan, O.; Ross, R.P.; O'Toole, P.W.; Shanahan, F.; Cotter, P.D. Targeting the Microbiota to Address Diet-Induced Obesity: A Time Dependent Challenge. PLoS ONE 2013, 8, e65790. [CrossRef] [PubMed]

23. Wang, K.; Jin, X.; You, M.; Tian, W.; Leu, R.; Topping, D.; Conlon, M.; Wu, L.; Hu, F. Dietary Propolis Ameliorates Dextran Sulfate Sodium-Induced Colitis and Modulates the Gut Microbiota in Rats Fed a Western Diet. Nutrients 2017, 9, 875. [CrossRef] [PubMed]

24. Roquetto, A.R.; Monteiro, N.E.S.; Moura, C.S.; Toreti, V.C.; de Pace, F.; Santos, A.D.; Park, Y.K.; Amaya-Farfan, J. Green propolis modulates gut microbiota, reduces endotoxemia and expression of TLR4 pathway in mice fed a high-fat diet. Food Res. Int. 2015, 76, 796-803. [CrossRef] [PubMed]

25. Zheng, Y.; Wu, Y.; Chen, X.; Jiang, X.; Wang, K.; Hu, F. Chinese Propolis Exerts Anti-Proliferation Effects in Human Melanoma Cells by Targeting NLRP1 Inflammatory Pathway, Inducing Apoptosis, Cell Cycle Arrest, and Autophagy. Nutrients 2018, 10, 1170. [CrossRef]

26. Deng, T.; Lyon, C.J.; Bergin, S.; Caligiuri, M.A.; Hsueh, W.A. Obesity, Inflammation, and Cancer. Annu. Rev. Pathol. 2016, 11, 421-449. [CrossRef]

27. Yudkin, J.S.; Kumari, M.; Humphries, S.E.; Mohamed-Ali, V. Inflammation, obesity, stress and coronary heart disease: Is interleukin-6 the link? Atherosclerosis 2000, 148, 209-214. [CrossRef]

28. Wanless, I.R.; Lentz, J.S. Fatty liver hepatitis (steatohepatitis) and obesity: An autopsy study with analysis of risk factors. Hepatology 1990, 12, 1106-1110. [CrossRef]

29. Weyer, C.; Funahashi, T.; Tanaka, S.; Hotta, K.; Matsuzawa, Y.; Pratley, R.E.; Tataranni, P.A. Hypoadiponectinemia in obesity and type 2 diabetes: Close association with insulin resistance and hyperinsulinemia. J. Clin. Endocrinol. Metab. 2001, 86, 1930-1935. [CrossRef]

30. Saito, M. Human brown adipose tissue: Regulation and anti-obesity potential. Endocr. J. 2014, 61, 409-416. [CrossRef]

31. Aoi, W.; Hosogi, S.; Niisato, N.; Yokoyama, N.; Hayata, H.; Miyazaki, H.; Kusuzaki, K.; Fukuda, T.; Fukui, M.; Nakamura, N.; et al. Improvement of insulin resistance, blood pressure and interstitial $\mathrm{pH}$ in early developmental stage of insulin resistance in OLETF rats by intake of propolis extracts. Biochem. Biophys. Res. Commun. 2013, 432, 650-653. [CrossRef] [PubMed]

32. Zamami, Y.; Takatori, S.; Koyama, T.; Goda, M.; Iwatani, Y.; Doi, S.; Kawasaki, H. Effect of propolis on insulin resistance in fructose-drinking rats. Yakugaku Zasshi 2007, 127, 2065-2073. [CrossRef] [PubMed]

33. Li, Y.; Chen, M.; Xuan, H.; Hu, F. Effects of encapsulated propolis on blood glycemic control, lipid metabolism, and insulin resistance in type 2 diabetes mellitus rats. Evid. Based Complement. Altern. Med. 2012, 2012, 981896. [CrossRef] [PubMed]

34. Rea, D.; Coppola, G.; Palma, G.; Barbieri, A.; Luciano, A.; Del Prete, P.; Rossetti, S.; Berretta, M.; Facchini, G.; Perdonà, S.; et al. Microbiota effects on cancer: From risks to therapies. Oncotarget 2018, 9, 17915-17927. [CrossRef] [PubMed] 
35. Marín, L.; Miguélez, E.M.; Villar, C.J.; Lombó, F. Bioavailability of Dietary Polyphenols and Gut Microbiota Metabolism: Antimicrobial Properties. BioMed Res. Int. 2015, 2015, 905215. [CrossRef] [PubMed]

36. Manach, C.; Williamson, G.; Morand, C.; Scalbert, A.; Rémésy, C. Bioavailability and bioefficacy of polyphenols in humans. I. Review of 97 bioavailability studies. Am. J. Clin. Nutr. 2005, 81, 230S-242S. [CrossRef]

37. Lee, H.; Ko, G. Effect of Metformin on Metabolic Improvement and Gut Microbiota. Appl. Environ. Microbiol. 2014, 80, 5935-5943. [CrossRef]

38. Xu, P.; Wang, J.; Hong, F.; Wang, S.; Jin, X.; Xue, T.; Jia, L.; Zhai, Y. Melatonin prevents obesity through modulation of gut microbiota in mice. J. Pineal Res. 2017, 62, e12399. [CrossRef]

39. Schwiertz, A.; Taras, D.; Schäfer, K.; Beijer, S.; Bos, N.A.; Donus, C.; Hardt, P.D. Microbiota and SCFA in Lean and Overweight Healthy Subjects. Obesity 2009, 18, 190-195. [CrossRef]

40. Arumugam, M.; Raes, J.; Pelletier, E.; Le Paslier, D.; Yamada, T.; Mende, D.R.; Fernandes, G.R.; Tap, J.; Bruls, T.; Batto, J.-M.; et al. Enterotypes of the human gut microbiome. Nature 2011, 473, 174-180. [CrossRef]

41. Qin, J.; Li, Y.; Cai, Z.; Li, S.; Zhu, J.; Zhang, F.; Liang, S.; Zhang, W.; Guan, Y.; Shen, D.; et al. A metagenome-wide association study of gut microbiota in type 2 diabetes. Nature 2012, 490, 55-60. [CrossRef] [PubMed]

42. Donaldson, G.P.; Lee, S.M.; Mazmanian, S.K. Gut biogeography of the bacterial microbiota. Nat. Rev. Microbiol. 2016, 14, 20-32. [CrossRef] [PubMed]

43. Biddle, A.; Stewart, L.; Blanchard, J.; Leschine, S. Untangling the Genetic Basis of Fibrolytic Specialization by Lachnospiraceae and Ruminococcaceae in Diverse Gut Communities. Diversity 2013, 5, 627-640. [CrossRef]

44. Shang, Q.; Shan, X.; Cai, C.; Hao, J.; Li, G.; Yu, G. Dietary fucoidan modulates the gut microbiota in mice by increasing the abundance of Lactobacillusand Ruminococcaceae. Food Funct. 2016, 7, 3224-3232. [CrossRef] [PubMed]

45. Leclercq, S.; Matamoros, S.; Cani, P.D.; Neyrinck, A.M.; Jamar, F.; Stärkel, P.; Windey, K.; Tremaroli, V.; Bäckhed, F.; Verbeke, K.; et al. Intestinal permeability, gut-bacterial dysbiosis, and behavioral markers of alcohol-dependence severity. Proc. Natl. Acad. Sci. USA 2014, 111, E4485-E4493. [CrossRef]

46. Duncan, B.B.; Schmidt, M.I.; Pankow, J.S.; Ballantyne, C.M.; Couper, D.; Vigo, A.; Hoogeveen, R.; Folsom, A.R.; Heiss, G. Atherosclerosis Risk in Communities Study Low-grade systemic inflammation and the development of type 2 diabetes: The atherosclerosis risk in communities study. Diabetes 2003, 52, 1799-1805. [CrossRef]

47. Thuy, S.; Ladurner, R.; Volynets, V.; Wagner, S.; Strahl, S.; Königsrainer, A.; Maier, K.-P.; Bischoff, S.C.; Bergheim, I. Nonalcoholic fatty liver disease in humans is associated with increased plasma endotoxin and plasminogen activator inhibitor 1 concentrations and with fructose intake. J. Nutr. 2008, 138, 1452-1455. [CrossRef]

48. Manco, M.; Putignani, L.; Bottazzo, G.F. Gut microbiota, lipopolysaccharides, and innate immunity in the pathogenesis of obesity and cardiovascular risk. Endocr. Rev. 2010, 31, 817-844. [CrossRef]

49. Harte, A.L.; da Silva, N.F.; Creely, S.J.; McGee, K.C.; Billyard, T.; Youssef-Elabd, E.M.; Tripathi, G.; Ashour, E.; Abdalla, M.S.; Sharada, H.M.; et al. Elevated endotoxin levels in non-alcoholic fatty liver disease. J. Inflamm. (Lond.) 2010, 7, 15. [CrossRef]

50. Peña, J.A.; Versalovic, J. Lactobacillus rhamnosus GG decreases TNF-alpha production in lipopolysaccharide-activated murine macrophages by a contact-independent mechanism. Cell. Microbiol. 2003, 5, 277-285. [CrossRef]

51. Yadav, H.; Jain, S.; Sinha, P.R. Antidiabetic effect of probiotic dahi containing Lactobacillus acidophilus and Lactobacillus casei in high fructose fed rats. Nutrition 2007, 23, 62-68. [CrossRef] [PubMed]

52. Haberer, P.; du Toit, M.; Dicks, L.M.T.; Ahrens, F.; Holzapfel, W.H. Effect of potentially probiotic lactobacilli on faecal enzyme activity in minipigs on a high-fat, high-cholesterol diet-A preliminary in vivo trial. Int. J. Food Microbiol. 2003, 87, 287-291. [CrossRef]

53. Rodes, L. Effect of Probiotics Lactobacillus and Bifidobacterium on Gut-Derived Lipopolysaccharides and Inflammatory Cytokines: An In Vitro Study Using a Human Colonic Microbiota Model. J. Microbiol. Biotechnol. 2013, 23, 518-526. [CrossRef]

54. Kitchens, R.L.; Thompson, P.A.; Munford, R.S.; O'Keefe, G.E. Acute inflammation and infection maintain circulating phospholipid levels and enhance lipopolysaccharide binding to plasma lipoproteins. J. Lipid Res. 2003, 44, 2339-2348. [CrossRef] [PubMed]

55. Burger-van Paassen, N.; Vincent, A.; Puiman, P.J.; van der Sluis, M.; Bouma, J.; Boehm, G.; van Goudoever, J.B.; van Seuningen, I.; Renes, I.B. The regulation of intestinal mucin MUC2 expression by short-chain fatty acids: Implications for epithelial protection. Biochem. J. 2009, 420, 211-219. [CrossRef] 
56. Yin, J.; Li, Y.; Han, H.; Chen, S.; Gao, J.; Liu, G.; Wu, X.; Deng, J.; Yu, Q.; Huang, X.; et al. Melatonin reprogramming of gut microbiota improves lipid dysmetabolism in high-fat diet-fed mice. J. Pineal Res. 2018, 61, e12524. [CrossRef]

57. Franconi, F.; Brunelleschi, S.; Steardo, L.; Cuomo, V. Gender differences in drug responses. Pharmacol. Res. 2007, 55, 81-95. [CrossRef]

58. Gelineau, R.R.; Arruda, N.L.; Hicks, J.A.; Monteiro De Pina, I.; Hatzidis, A.; Seggio, J.A. The behavioral and physiological effects of high-fat diet and alcohol consumption: Sex differences in C57BL6/J mice. Brain Behav. 2017, 7, e00708. [CrossRef]

59. Matsuzawa, Y.; Funahashi, T.; Nakamura, T. Molecular mechanism of metabolic syndrome X: Contribution of adipocytokines adipocyte-derived bioactive substances. Ann. N. Y. Acad. Sci. 1999, 892, 146-154. [CrossRef]

60. Patterson, E.; Ryan, P.M.; Cryan, J.F.; Dinan, T.G.; Ross, R.P.; Fitzgerald, G.F.; Stanton, C. Gut microbiota, obesity and diabetes. Postgrad. Med. J. 2016, 92, 286-300. [CrossRef]

61. Snowberg, L.K.; Hirsch, P.E.; Lauber, C.L.; Org, E.; Parks, B.; Lusis, A.J.; Knight, R.; Caporaso, J.G.; Svanbäck, R.; Bolnick, D.I. Individual diet has sex-dependent effects on vertebrate gut microbiota. Nat. Commun. 2014, 5, 4500 .

62. Ibnou-Zekri, N.; Blum, S.; Schiffrin, E.J.; von der Weid, T. Divergent patterns of colonization and immune response elicited from two intestinal Lactobacillus strains that display similar properties in vitro. Infect. Immun. 2003, 71, 428-436. [CrossRef] [PubMed]

63. Kang, J.-H.; Yun, S.-I.; Park, M.-H.; Park, J.-H.; Jeong, S.-Y.; Park, H.-O. Anti-Obesity Effect of Lactobacillus gasseri BNR17 in High-Sucrose Diet-Induced Obese Mice. PLoS ONE 2013, 8, e54617. [CrossRef] [PubMed]

64. Lee, J.E.; Lee, S.; Lee, H.; Song, Y.-M.; Lee, K.; Han, M.J.; Sung, J.; Ko, G. Association of the vaginal microbiota with human papillomavirus infection in a Korean twin cohort. PLoS ONE 2013, 8, e63514. [CrossRef]

65. Chen, K.L.; Madak-Erdogan, Z. Estrogen and Microbiota Crosstalk: Should We Pay Attention? Trends Endocrinol. Metab. 2016, 27, 752-755. [CrossRef]

66. Blasco-Baque, V.; Serino, M.; Vergnes, J.-N.; Riant, E.; Loubieres, P.; Arnal, J.-F.; Gourdy, P.; Sixou, M.; Burcelin, R.; Kemoun, P. High-Fat Diet Induces Periodontitis in Mice through Lipopolysaccharides (LPS) Receptor Signaling: Protective Action of Estrogens. PLoS ONE 2012, 7, e48220. [CrossRef]

67. Cipolletti, M.; Solar Fernandez, V.; Montalesi, E.; Marino, M.; Fiocchetti, M. Beyond the Antioxidant Activity of Dietary Polyphenols in Cancer: The Modulation of Estrogen Receptors (ERs) Signaling. Int. J. Mol. Sci. 2018, 19, 2624. [CrossRef]

68. Song, Y.S.; Jin, C.; Jung, K.J.; Park, E.-H. Estrogenic effects of ethanol and ether extracts of propolis. J. Ethnopharmacol. 2002, 82, 89-95. [CrossRef]

69. Zingue, S.; Nde, C.B.M.; Michel, T.; Ndinteh, D.T.; Tchatchou, J.; Adamou, M.; Fernandez, X.; Fohouo, F.-N.T.; Clyne, C.; Njamen, D. Ethanol-extracted Cameroonian propolis exerts estrogenic effects and alleviates hot flushes in ovariectomized Wistar rats. BMC Complement. Altern. Med. 2017, 17, 65. [CrossRef] 